\title{
GLOBAL GLAMPING
}

\author{
Autores: \\ Diego Alejandro Benavides Fonseca, Andrés Merchán Alvear y \\ Javier Alexander Torres Munevar.
}

\author{
Dirigido por: \\ Johanna Carolina Suarez Guzmán
}

Facultad de Administración de Empresas.

Bogotá

2018 


\section{Resumen Ejecutivo}

Global Glamping ofrece la oportunidad de vivir la experiencia del servicio de campismo sin perder las comodidades del ambiente urbano, alojándose en un agradable y cálido domo transparente que los conectará y hará que vivan al detalle una experiencia de campismo diferente.

Se encuentra ubicada en la región de la Calera, ya que es una zona que cuenta con una amplia riqueza hídrica proporcionada por el rio blanco y el páramo de Chingaza desde sus diversas y hermosas cascadas, con la posibilidad de visualizar sus hermosos paisajes de los cuales se encontrarán con senderos ancestrales que unifican los llanos orientales con el centro del país.

Pensando en todos aquellos clientes que tomarán la decisión de vivir esta agradable experiencia, Global Glamping contará con alianzas estratégicas que serán de vital importancia para ofrecer un mejor servicio, en donde se incluya la posibilidad de poder realizar divertidas actividades tales como: cabalgatas, senderismo, excursiones educativas, excursiones empresariales, avistamiento de aves, caminatas, yoga, entre otras.

Global Glamping es una empresa que busca potenciar el turismo mediante el desarrollo de un servicio comúnmente no conocido en la región de Bogotá-Cundinamarca, diversificando la oferta y la experiencia turística, teniendo como énfasis el turismo de interés exclusivo, presentándose como una oportunidad de generar una alternativa en los planes del turismo Colombiano, ampliando con este servicio la entrada de turistas al país, generando de esta manera un el crecimiento económico del sector y la generación de nuevos empleos. 
Se tiene conocimiento de muchas empresas que presentan un servicio similar al de Global Glamping en la región de Cundinamarca, sin embargo, se busca ofrecer un valor diferencial por el cual ser reconocidos, en donde se enfoca al cliente en el cuidado, la importancia y la preservación del medio ambiente y la afectación que este tiene en la sociedad. 


\section{Tabla de Contenido}

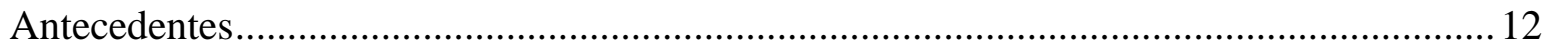

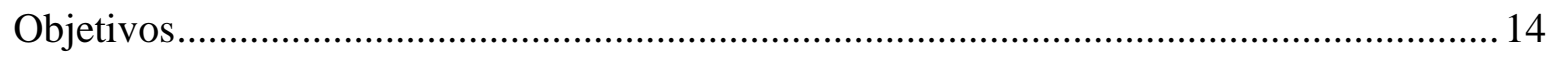

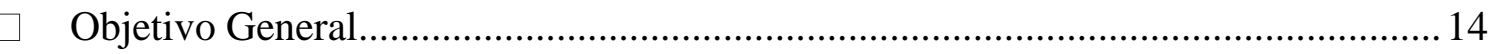

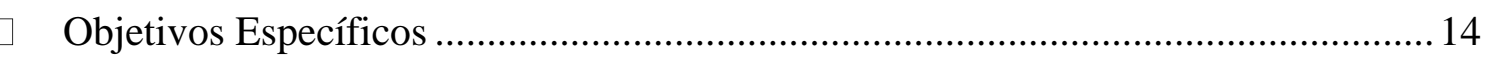

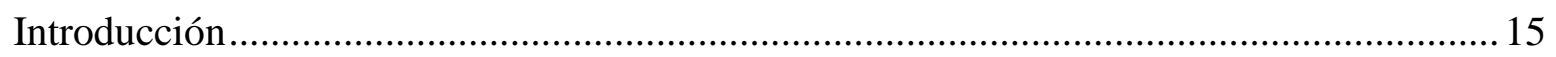

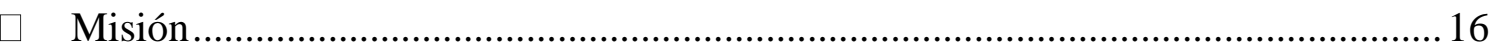

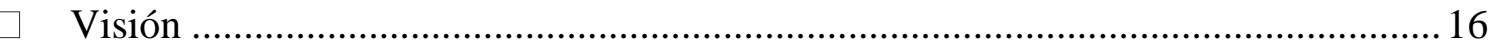

$\square \quad$ Valores Corporativos .................................................................................... 17

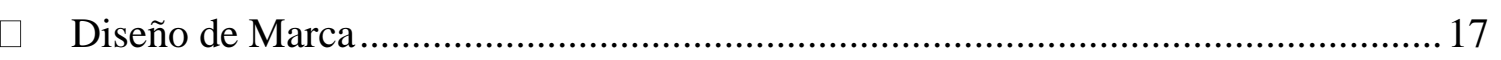

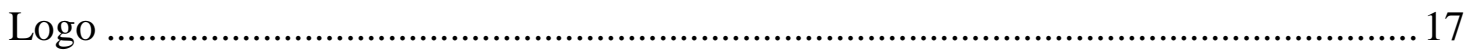

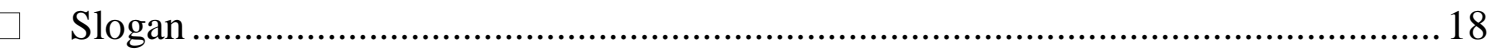

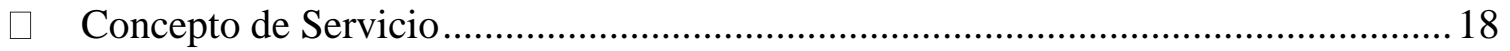

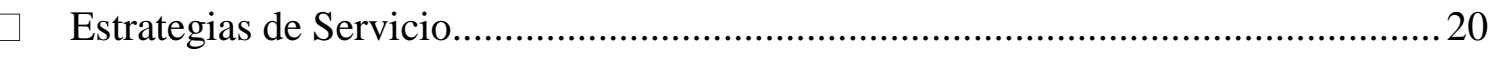

Análisis de Encuestas ...................................................................................... 21

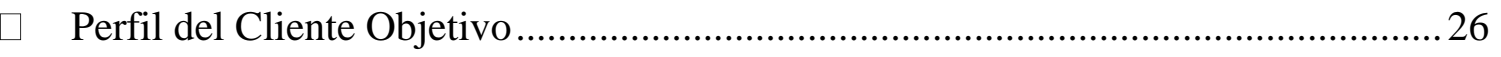

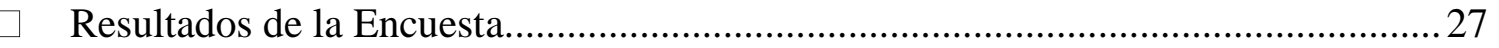

Análisis de Resultados................................................................................. 31

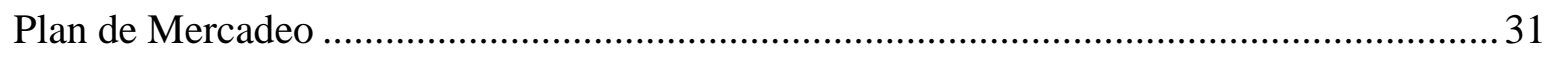




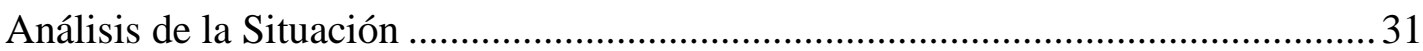

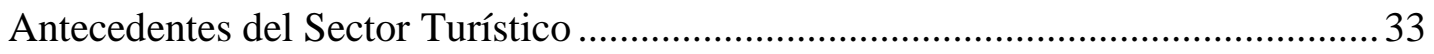

Panorama del sector Eco-turístico para el año 2017 - 2018 .................................... 35

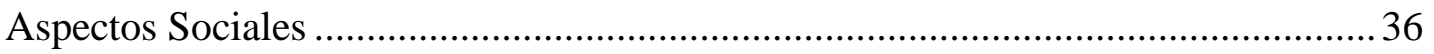

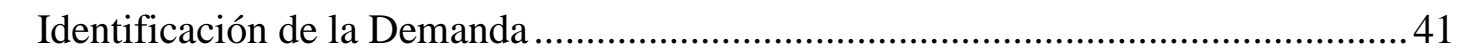

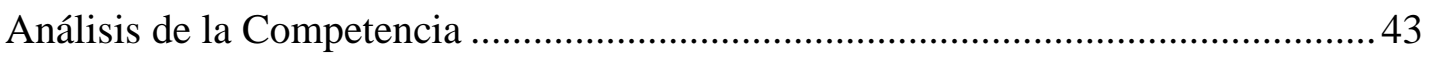

Competencia Sustituta - Alojamientos Ecoturísticos ............................................. 44

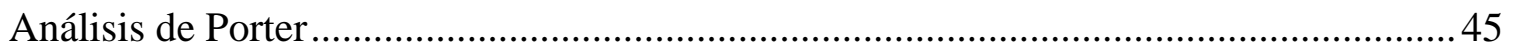

1. Poder de Negociación de los Compradores o Clientes...................................46

2. Poder de Negociación de los Proveedores o Vendedores..............................47

3. Amenaza de nuevos Competidores Entrantes .......................................... 47

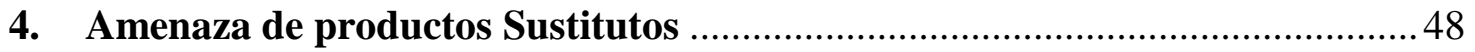

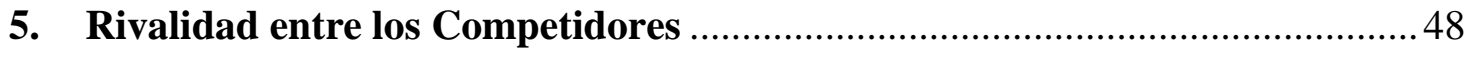

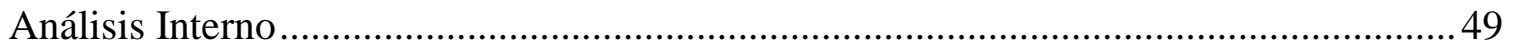

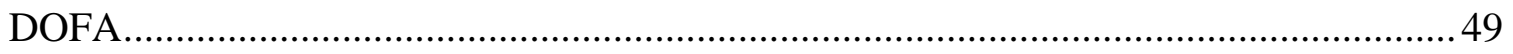

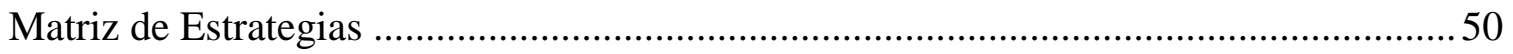

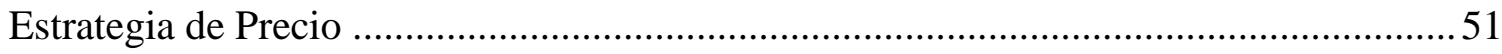

Aspectos Evaluados para la fijación del Precio .................................................52

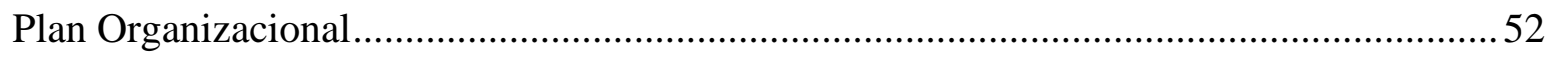

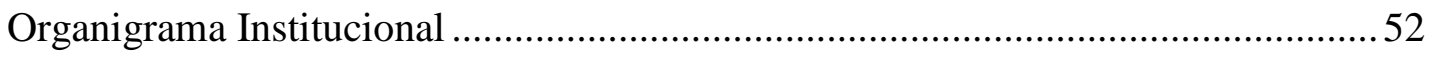




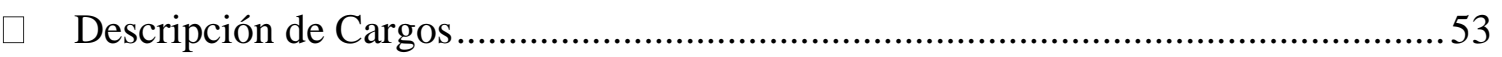

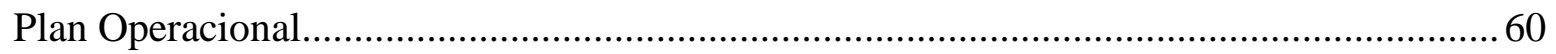

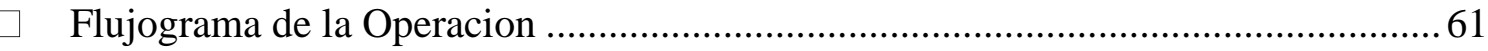

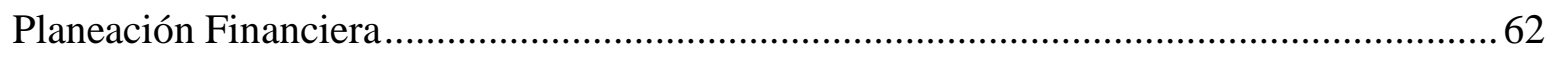

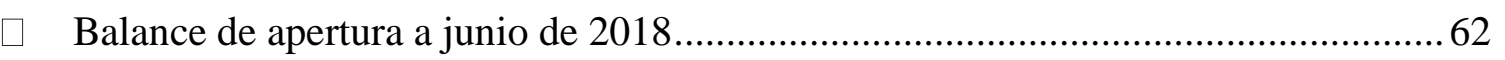

$\square \quad$ Balance general comparativo 2018 - 2022 .................................................... 63

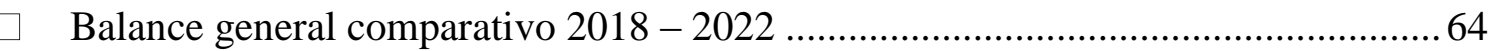

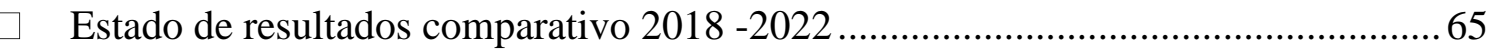

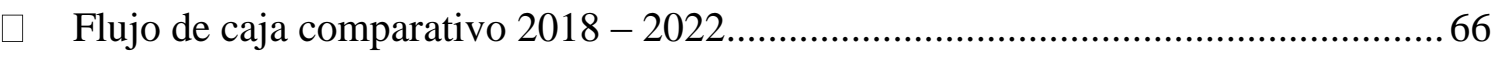

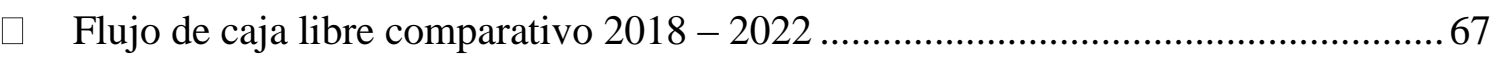

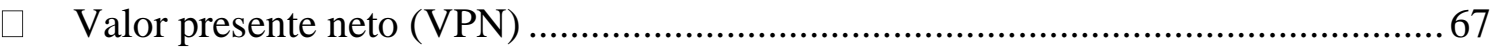

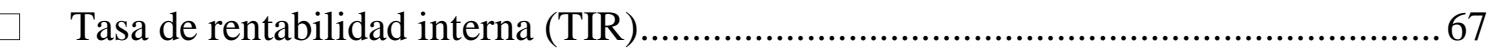

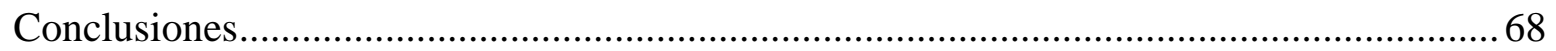

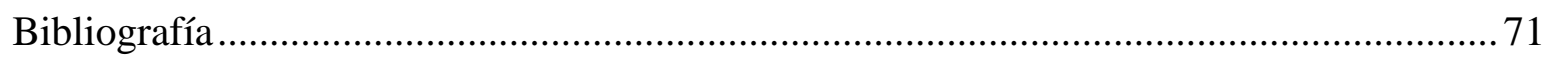




\section{Tabla de Ilustraciones}

Ilustración 1 Logo Preliminar - Autoria: Global Glamping .......................................... 17

Ilustración 2 Ejemplo de Glamping ....................................................................... 19

Ilustración 4: Estrategia - Arma tu plan - Autoría: Global Glamping ..............................20

Ilustración 6 Mapa de Estratificación Bogotá - Autoría: (Dinero, 2015) .......................... 21

Ilustración 7: Ruta de llegada a Global Glamping desde Chapinero................................ 24

Ilustración 8: Formula para medir el Tamaño de la Población.......................................... 25

Ilustración 9 Discriminación porcentual de la Ocupación de los Encuestados - Autoría

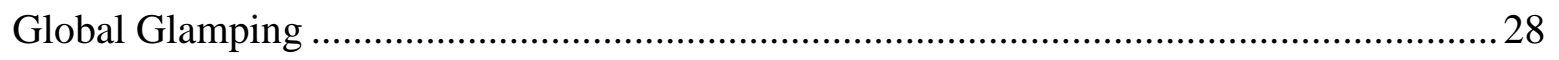

Ilustración 10 Discriminación porcentual de la Edad de los Encuestados - Autoría Global

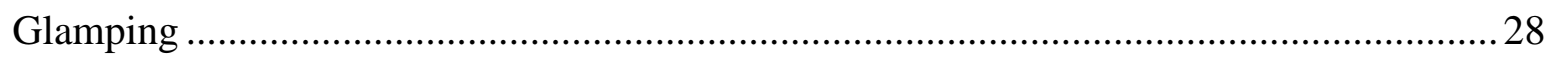

Ilustración 11 Discriminación porcentual de la aceptabilidad de Global Glamping en los

encuestados - Autoría Global Glamping ..................................................................2 29

Ilustración 12 Discriminación porcentual de la elección de Glamping - Autoria Global

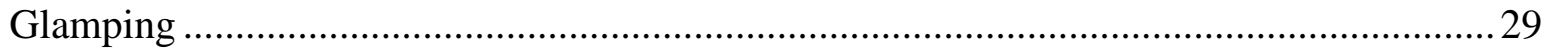

Ilustración 13 Discriminación porcentual de la elección de Acompañante según

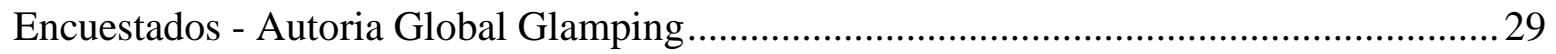

Ilustración 14 Discriminación porcentual al servicio necesario según Encuestados - Autoria

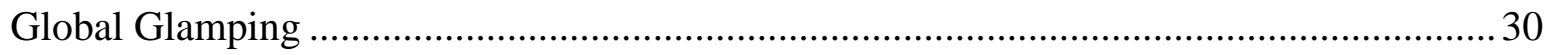

Ilustración 15 Discriminación porcentual según rango de precios sugerido por los

encuestados - Autoria Global Glamping ............................................................. 30

Ilustración 16 Crecimiento porcentual del PIB 2010 - 2016 - Autoria CITUR 2016 ...........34 
Ilustración 17 Crecimiento del PIB 2010 - 2016 - Autoria CITUR 2016 ........................... 34

Ilustración 18 Ciclo de vida sub-productos del Turismo de Naturaleza - Basado en: Informe

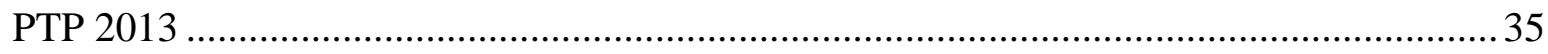

Ilustración 19 Distribución Porcentual de Motivos de Visitas Bogotá - Autoria Global

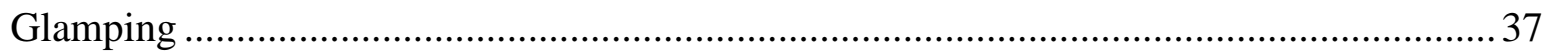

Ilustración 20 Excursión por concepto de Motivo de Viaje - Bogotá - Autoria Global

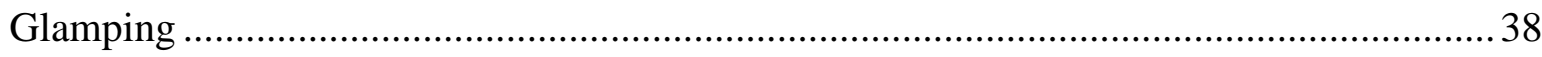

Ilustración 21 Llegada de Visitantes Extranjeros No Residentes en Bogotá - Basado en:

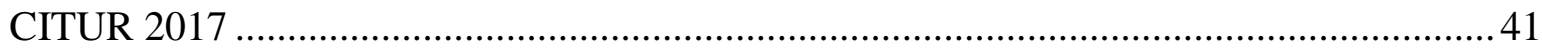

Ilustración 22: Estructuras 5 Fuerzas de Porter - Autoría Global Glamping........................46

Ilustración 23. Análisis Cruce de Estrategias DOFA. Autoría Global Glamping ................51

Ilustración 24: Conceptos Evaluados para la Fijación del Precio - Autoría: Global Glamping

Ilustración 25 Organigrama - Autoria: Global Glamping ….......................................52

Ilustración 26 Flujograma de Servicio - Autoría Global Glamping .................................6 61 


\section{Tabla de Cuadros}

Tabla 1 Servicios de Global Glamping - Autoria Global Glamping ................................ 19

Tabla 2: tabla de Variables - formula "Tamaño de la Muestra" ........................................ 25

Tabla 3 Muestra de Población Objetivo - Autoría Global Glamping.................................26

Tabla 4 Caracteristicas del Cliente Objetivo - Autoria Global Glamping .........................22

Tabla 5 Discriminación por sexo población encuestada - Autoría Global Glamping ..........28

Tabla 6 Discriminacion cuantitativa de mejor servicio esperado por los encuestados -

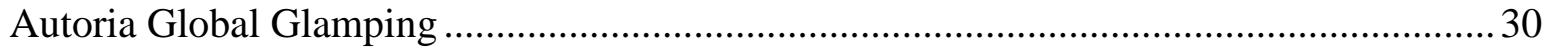

Tabla 7 Receptivo de viajeros en el transcurso del año 2017 - Basado en: MINCIT 201738

Tabla 8 Viajeros a Bogota 2016 - 2017 - Basado en: MINCIT 2017................................39

Tabla 9 Cantidad de viajeros segun rango de Meses 2016- 2017 - Basado en: MINCIT 2017

Tabla 10 Viajeros segun mejor mes de Visitas 2016 - 2017 - Basado en: MINCIT 2017 ... 39

Tabla 11 Motivo de Vacaciones 2016 - 2017 - Basado en: MINCIT 2017....................... 40

Tabla 12 Llegada de visitantes Extranjeros No Residentes en Bogotá - Basado en: MINCIT

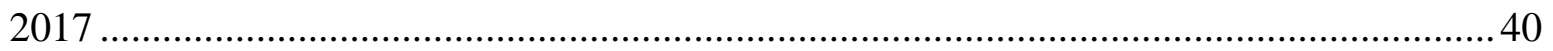

Tabla 13 Competencia Directa - Autoria Global Glamping ......................................... 44

Tabla 14 Competencia Sustituta - Autoria Global Glamping....................................... 45

Tabla 15 Análisis DOFA Autoría: Global Glamping ................................................50

Tabla 16 Descripcion de cargo (Recepcionista) - Autoria: Global Glamping ...................53

Tabla 17 Descripcion de cargo (Coordinador Administrativo) - Autoria: Global Glamping 
Tabla 18 Descripcion de cargo (Gerente General y Financiero) - Autoria: Global Glamping 55

Tabla 19 Descripcion de cargo (Coordinador de Mercadeo y Ventas) - Autoria: Global

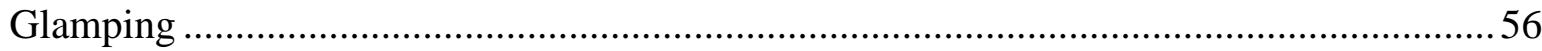

Tabla 20 Descripcion de cargo (Agente de Mantenimiento) - Autoria: Global Glamping .57

Tabla 21 Descripcion de cargo (Guia) - Autoria: Global Glamping .................................58

Tabla 22 Descripcion de cargo (Camarero) - Autoria: Global Glamping .........................59

Tabla 23 Descripcion de cargo (Supervisor) - Autoria: Global Glamping........................59

Tabla 24 Descripcion de cargo (Agente de Seguridad) - Autoria: Global Glamping ........60

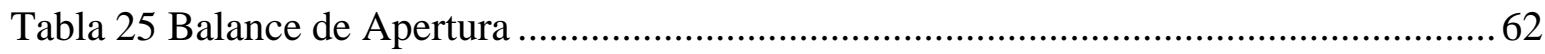

Tabla 26 Balance General - Autoria: Global Glamping ................................................ 64

Tabla 27 Estado de Resultados - Autoria: Global Glamping ........................................... 65

Tabla 28 Tasa Interna de Retorno (TIR) - Autoria: Global Glamping ............................. 67 


\section{Antecedentes}

No se tiene un conocimiento exacto del origen oficial del Glamping, no obstante y según el libro (Sciosia, 2015), existen varios indicios que exponen su origen a lo largo de la historia, remontándose en primera instancia al siglo XII, época de la Edad Media, donde se describían aquellas tiendas móviles de la nobleza Europea que servían de refugio en sus viajes a la antes conocida Asia Central adaptando el nombre de "Imperial Camps", pese a la importancia que estas llegaron a presentar en ese momento y a la adaptación lujosa que miles de personas que trabajaban en ese entonces en el sector textil realizaron a estos alojamientos, diferentes imperios adaptaron la idea para ser usada como refugio de sus tropas en combate, no obstante, se tiene evidencia de que siglos atrás el Imperio Otomano más conocido por ser el Imperio de Turquía, 200 a.C, utilizaban tiendas móviles para la presentación de ceremonias culturales, las cuales contaban con tejidos en seda, bordados, alfombras y diversos muebles de exagerado valor que servían como atractivo para este tipo de reuniones.

El uso ceremonial más importante del cual dio origen el Glamping, tuvo su participación en el siglo XI en la cultura China, en donde aún el Museo del Palacio en la Ciudad Prohibida de Pekín, se visualizan cuadros de la emperatriz Song dando a luz en una Tienda-Palacio, rodeada de unas decenas de tiendas más pequeñas.

Después de varios siglos de guerra, las tiendas de campaña empezaron a verse mal vistas y a perder su uso, no fue hasta mediados del siglo XIX, con las primeras expediciones de los Americanos al continente Africano volvieron a retomar su uso, y hasta el siglo XX estas tiendas empezaron a ser utilizadas como alojamientos turísticos llegando a un punto donde se empezó a implementar una variedad de ahora denominados Glamping 
cubriendo los diferentes gustos y necesidades de las personas que usaban estos hospedajes para vivir una experiencia turística.

Actualmente existen diversos tipos de alojamientos para realizar Glamping de los cuales podemos encontrar: casas en el árbol, yurtas o también conocidas como viviendas de nómadas, tiendas safari, auto caravana, tipis, casas domo, iglús y tiendas de campaña. Global Glamping específicamente prestara el servicio de alojamiento de Domos transparentes en los cuales podrá tener la oportunidad de disfrutar de una extraordinaria vista y una conexión excepcional con la naturaleza, así mismo disfrutar de un hermoso atardecer y un cielo estrellado desde la comodidad de una cama King con su acompañante. "El Glamping puede ser conocido también como el campismo de los Millenians", esto según el periódico Argentino Infobae, (Infobae, 2018), que para el siglo XXI es un negocio que requiere de implementación e inversión para su posterior comercialización e impacto en la sociedad. 


\section{Objetivos}

\section{- Objetivo General}

Desarrollar el plan de negocio de una empresa que preste servicios de Glamping en el municipio de la Calera, el cual sea sostenible en el tiempo y cuente con una viabilidad económica.

\section{- Objetivos Específicos}

- Determinar la viabilidad económica del proyecto en un periodo de 5 años.

- Identificar la población objetivo a la cual va dirigido el servicio que se presta.

- Establecer una estructura organizacional para determinar las actividades a realizar.

- Generar un plan operativo en función del control de la operación del proyecto. 


\section{Introducción}

Tomando como referencia la pregunta del ¿Por qué visitar Colombia para realizar turismo? Presentada por Procolombia (Proexport, s.f) tanto para extranjeros como para colombianos, teniendo como finalidad que personas de diferentes ciudades del mundo asistan a ser parte de esta recreativa pero relajante experiencia, se presenta a Colombia como un país con una extravagante variedad de flora y fauna natural, que alberga casi el $10 \%$ de especies conocidas, que se caracteriza por contar con fascinantes especies que no se ven en otras partes del mundo como lo es el caso del cóndor andino, considerada como una de las aves más grandes del mundo. Colombia cuenta con una serie de majestuosas montañas donde se pueden apreciar alrededor de 1889 especies de aves diferentes de las cuales 71 de estas, son especies únicas en el mundo, adicionalmente, nos damos el lujo de contar con 3000 especies de mariposas diferentes.

Colombia ha contado con aspectos de vital importancia en los últimos años que hace de este, un país con una oportunidad amplia en términos turísticos, brindarle al visitante un ambiente seguro y relajante, como lo son el caso de la firma del tratado de Paz, la renovación de la nueva reforma tributaria que según la presidencia de la república (Republica P. d., 2017), generará un impulso a diferentes municipio que no han tenido la oportunidad de recibir inversión para el crecimiento potencial en términos de turismo, adicionalmente, fomentará el aumento del empleo y mayores posibilidades de un crecimiento porcentual del sector a comparación con los años pasados.

Para las todas aquellas personas que deseen vivir una experiencia turística, Global Glamping les presenta la posibilidad de conocer un paraíso natural como lo es el territorio de la Calera, basados en la información proporcionada por (Calera, 2017), se promueve a 
los usuarios de este servicio la oportunidad de conocer la riqueza hídrica proporcionada por el rio blanco y el páramo de Chingaza desde sus diversas y hermosas cascadas, adicionalmente, visualizar sus hermosos paisajes de los cuales se encontrarán con senderos ancestrales que unifican los llanos orientales con el centro del país, además de interactuar con la exquisita riqueza de fauna y flora que se encuentra en el lugar y de compartir con diversos guías que culturalmente harán conocer historias y anécdotas del sector, ampliando de esta manera el conocimiento sobre los diferentes lugares que tendrán los usuarios de este servicio la oportunidad de visitar y por si fuera poco se alojarán en uno de los novedosos Domos transparentes con la posibilidad de visualizar todo el paisaje recostado desde su cama, contando con todos los servicios que necesita para que tenga una experiencia inolvidable, novedosa y enriquecedora, donde predomine la conexión del ser humano con la naturaleza y la excelente calidad del servicio.

\section{Planeación Estratégica}

\section{- Misión}

Somos una empresa que se dedica a la prestación de servicios de Glamping en el Municipio de la Calera, buscando brindarles a nuestros usuarios la oportunidad de vivir la experiencia de interactuar con la naturaleza desde un alojamiento novedoso sin perder las comodidades de un hotel 5 estrellas.

\section{- Visión}

En el año 2022 queremos ser los líderes en el mercado en prestación de servicios de Glampling eco-amigables, reconocidos por nuestros servicios únicos y experienciales. 
- Valores Corporativos

- Responsabilidad: Actuamos con sinceridad, en consecuencia con nuestros deberes con el medio ambiente y colaboradores

- Respeto: Escuchamos atentamente a nuestros clientes y colaboradores, siempre en busca de la armonía en las relaciones interpersonales.

- Confianza: Cumplimos con lo prometido, ofrecemos servicios de alta calidad, buscando siempre el bienestar del medio ambiente y nuestros clientes.

- Trabajo en equipo: Siempre con la confianza y el respeto que hay en nuestros colaboradores, cumpliremos cada una de nuestras metas y objetivos organizacionales.

- Honestidad: Ejecutamos todas nuestras operaciones con transparencia y equidad.

\section{- Diseño de Marca}

\section{Logo}

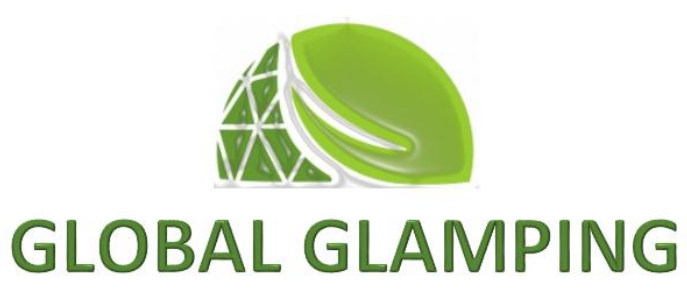

\section{GRANDES MOMENTOS}

Ilustración 1 Logo Preliminar - Autoria: Global Glamping

Este logo está basado en la conexión con la naturaleza y el medio ambiente, además de ello según Eva Héller autora del libro Psicología del Color (Heller, 2004), se trabaja el 
color verde en su interior por ser en la escala de colores, el que transmite sensaciones de relajación, serenidad y armonía.

\section{- Slogan}

\section{"Grandes Momentos"}

Con este slogan se piensa vender la idea de salir de lo rural y vivir una experiencia natural, por otra parte se incentiva al usuario a tener mayor cuidado con la naturaleza para la preservación del medio ambiente

\section{- Concepto de Servicio}

Global Glamping presenta la oportunidad de que sus clientes vivan una experiencia diferente, totalmente fuera a lo rural y lo cotidiano, una forma de acampar con estilo y elegancia contando con todas las comodidades al alcance de su mano, especial para personas con deseos de respirar aire puro, con grandes gustos por el encanto natural, aventureros y sobretodo que aprecien de la comodidad de las ciudad y la tranquilidad de la naturaleza.

Tomando como ejemplo las siguientes imágenes de Glamping que crea la empresa Shelter Dome de de China (Dome, s.f), serán de gran ayuda para los clientes brindándoles la oportunidad de tener comodidad, espacio y una gran vista sin la necesidad de salir de su burbuja. 


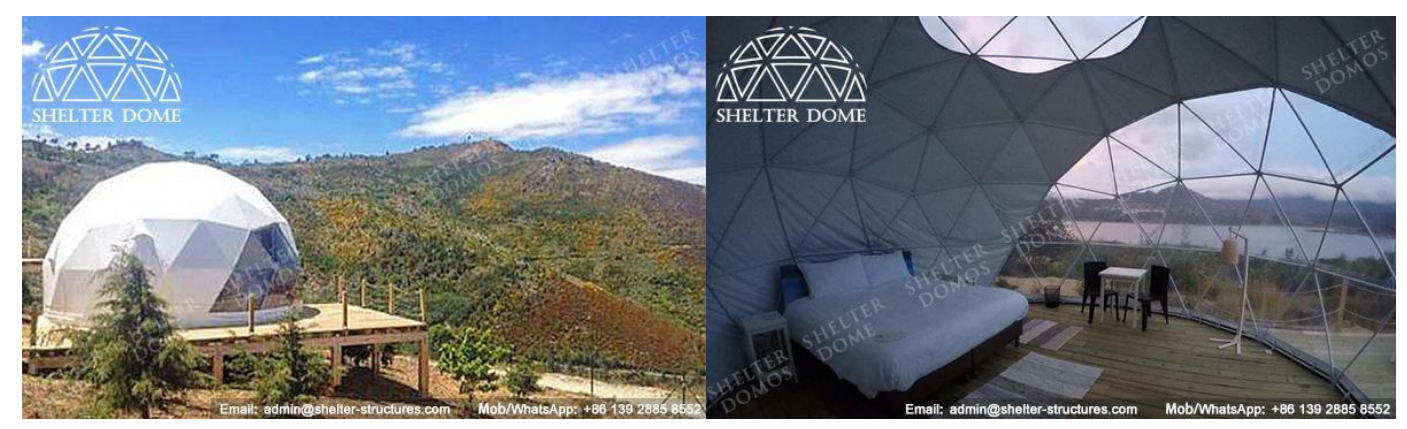

Ilustración 2 Ejemplo de Glamping

Además de esto, nuestros clientes contarán con la oportunidad de elegir dentro de diferentes actividades de las cuales podemos resaltar:

\begin{tabular}{|l|l|}
\hline SUBPRODUCTO & ACTIVIDAD \\
& Avistamiento de Aves \\
\hline \multirow{4}{*}{$\begin{array}{c}\text { Servicios } \\
\text { Complementarios }\end{array}$} & Foga \\
\cline { 2 - 2 } & Fogatas Nocturnas \\
\cline { 2 - 2 } & Cabalgatas \\
\hline & Excursiones Educacionales - Corporativas \\
\hline & Observación de Flora y Fauna \\
\hline & Senderismo \\
\hline & Ciclo montañismo \\
\hline & Parapente \\
\hline
\end{tabular}

Tabla 1 Servicios de Global Glamping - Autoria Global Glamping

Esto va ligado según el paquete que desee elegir en el cual tiene la oportunidad de además de la actividad de Camping - Glamping y Fogata Nocturna, adicionar otras 2 actividades para realizar gratuitamente y opcional 2 actividades que tendrán un costo adicional.

Con este tipo de actividades complementarias la persona vivirá momentos ya sean extremos o de relajación y tranquilidad $100 \%$ conectado con la naturaleza, buscando implementar el concepto en sus cabezas de "cuidado con el medio ambiente". 


\section{- Estrategias de Servicio}

"Arma tu Plan" es una estrategia que se presenta para que diferentes usuarios tengan la oportunidad de elegir 3 planes adicionales al de Gamping, con el fin de que puedan compartir con sus acompañantes otro tipo de actividades, entre las cuales se encuentran: Senderismo, Cabalgata, Ciclo-Montañismo, Yoga y Fogata Nocturna

Tienen igualmente la posibilidad de disfrutar por un precio mínimo, actividades de las cuales podemos destacar: Parapente, Rappel.

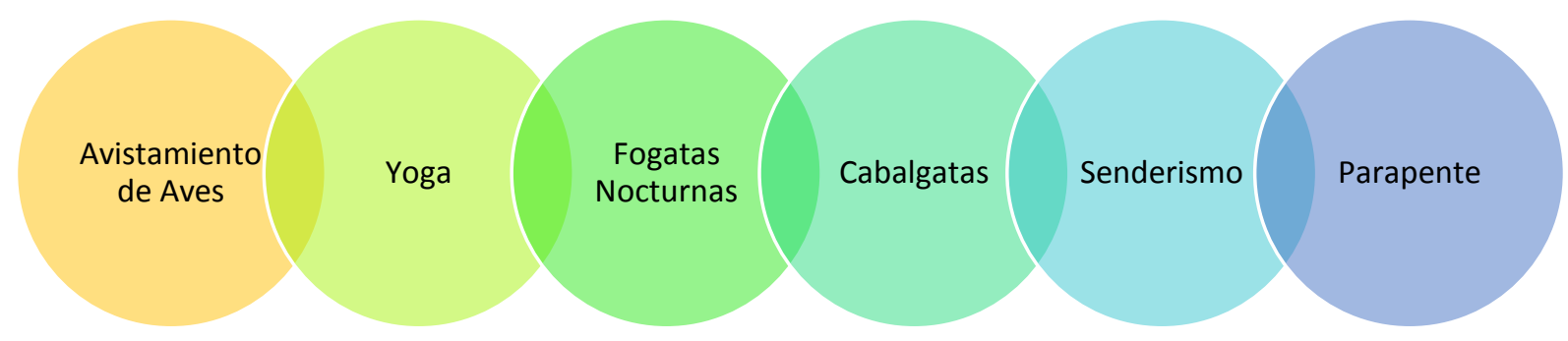

Ilustración 3: Estrategia - Arma tu plan - Autoría: Global Glamping

Esta iniciativa busca generar ingresos adicionales al valor inicial del plan, generando un contrato de concesión con aquellos aliados, buscando se nos remunere un $15 \%$ del valor del servicio por persona. 


\section{Análisis de Encuestas}

Para realizar el estudio de mercado tomamos la localidad de Chapinero, esta fue escogida ya que es una de las localidades más cercanas al municipio de La Calera, según la página oficial de la alcaldía de Bogotá-Chapinero se encuentra ubicada al Noroeste de Bogotá, esta se encuentra divida en tres subsectores: Chapinero Barrio, el Lago y el Chico, limita al norte con la calle 100 y la vía al municipio de La Calera, en el occidente limita con la avenida caracas y el eje vial de la autopista Norte, en el oriente limita con los municipios de la Calera y Choachí y en el sur limita con la localidad de Santa Fe y el río Arzobispo, tiene una extensión de 3898,96 hectáreas, un área rural de 2664,25 hectáreas y un área urbana de 1234,71 hectáreas, aproximadamente Chapinero cuenta aproximadamente con 166000 habitantes, esto según (Secretaria de Cultura, 2016).

\section{Mapa de Estratificación de Bogotá}

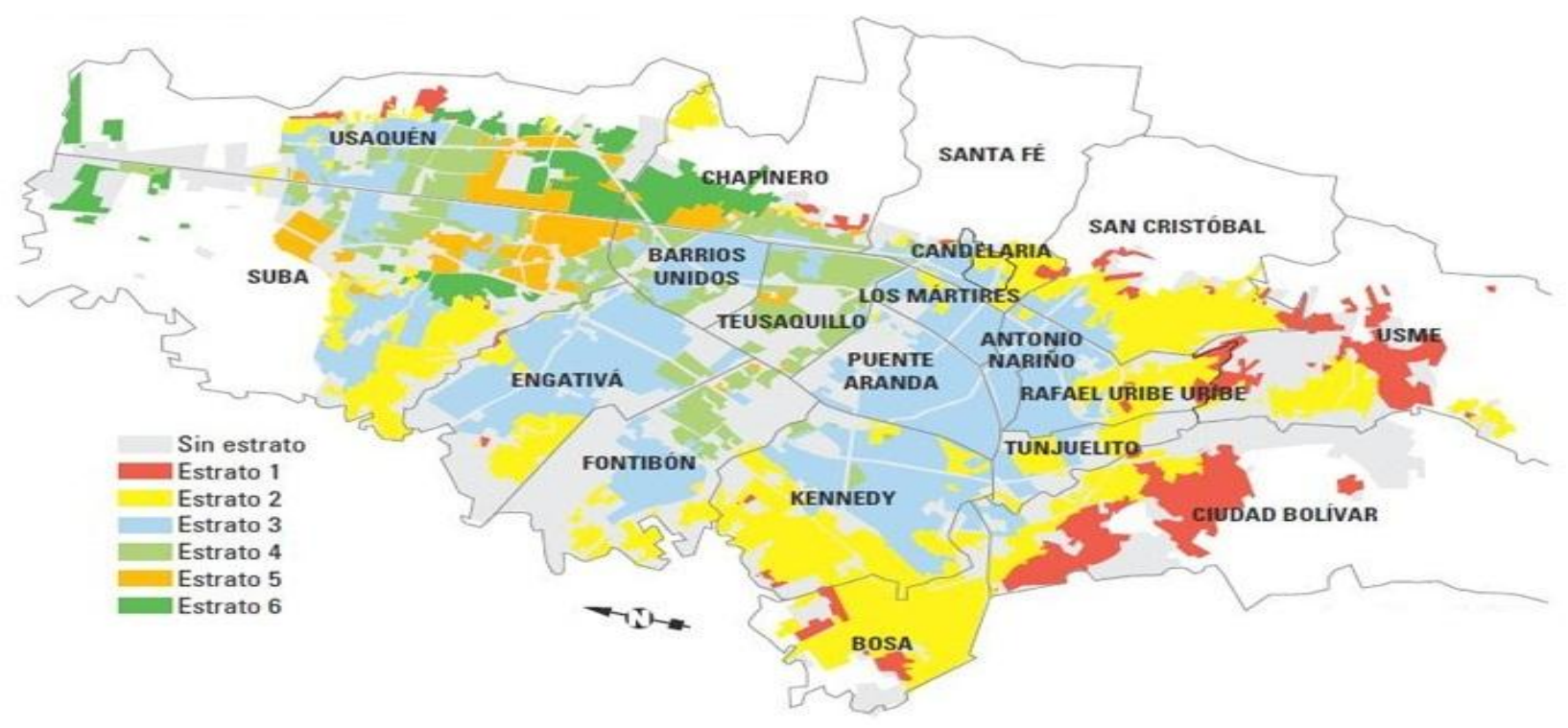




\section{Población Local.}

El número de habitantes de chapinero realizado en el último Censo del Dane del 2005 es de 122.089 personas, el 55\% (67.149) está constituido por Mujeres y el $45 \%$ (54.940) por Hombres.

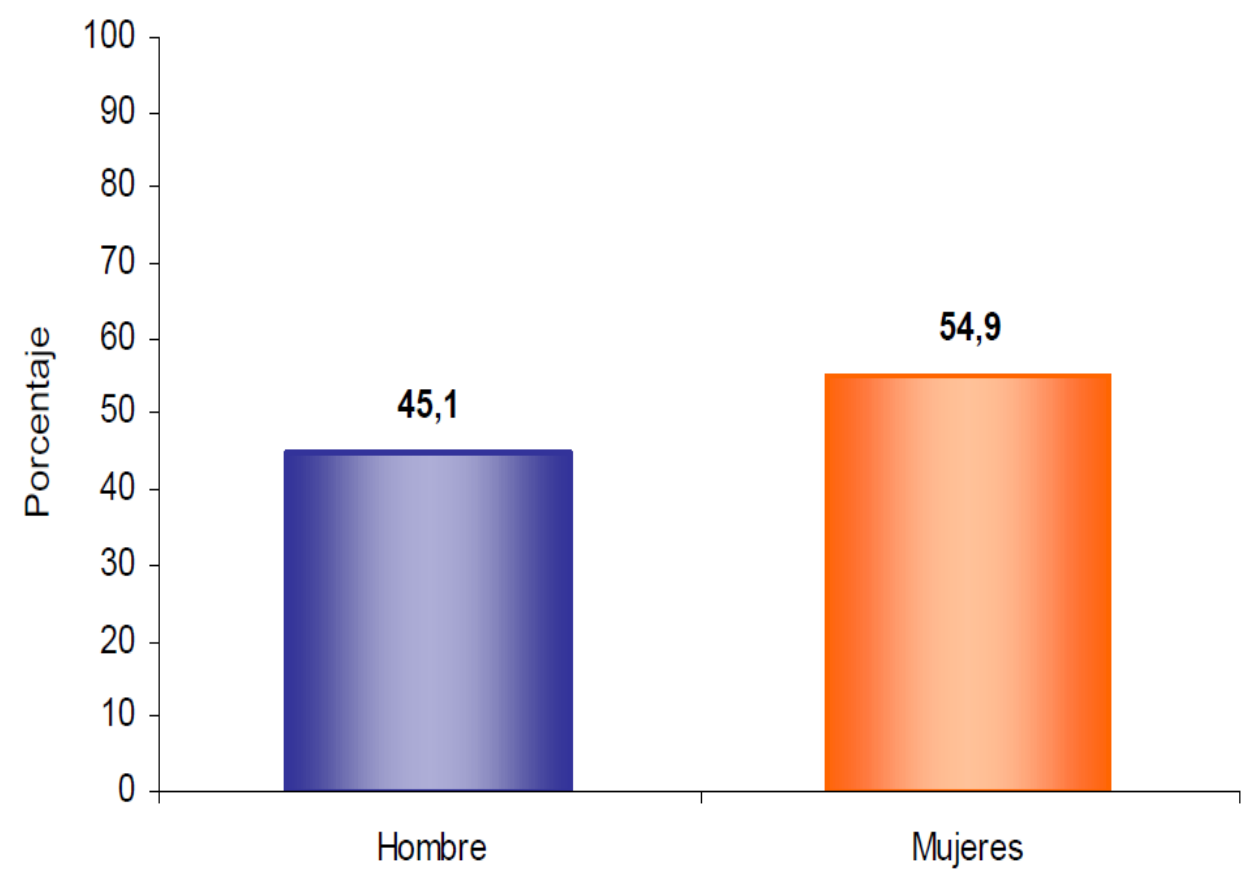

Ilustracion 2 Medición en porcentaje de número de hombres y Mujeres en la localidad de Chapinero - Tomado Boletín Dane año 2005

\section{Nivel socioeconómico}

Según el Dane en la Localidad de chapinero predomina la clase socioeconómica alta, el $45.8 \%$ de predios son de estrato 6, el $11.7 \%$ representa al estrato 5, el $30.8 \%$ corresponde al estrato 4, el $5.5 \%$ representa al estrato 3 , el $1.5 \%$ representan al estrato 1 y el $1.6 \%$ corresponde a predios no residenciales. 


\section{Educación Localidad Chapinero}

Según el Censo del Dane realizado en el 2005, el nivel de educación es el siguiente:

El 13.4\% (16359.926) de la población de Chapinero ha alcanzado primaria básica, el 21.8\% (26615.402) secundaria, el 34.7\% (42365) a alcanzado el nivel profesional y el $15.6 \%$ (19045.884) ha alcanzado niveles de especialización, maestría y doctorado, el 1.7\% (2075.513) no alcanzado nivel educativo, el 0.4\% (488) es normalista, el 4.5\% (5494) tienen educación técnica y 3.5\% (4273) Prescolar.

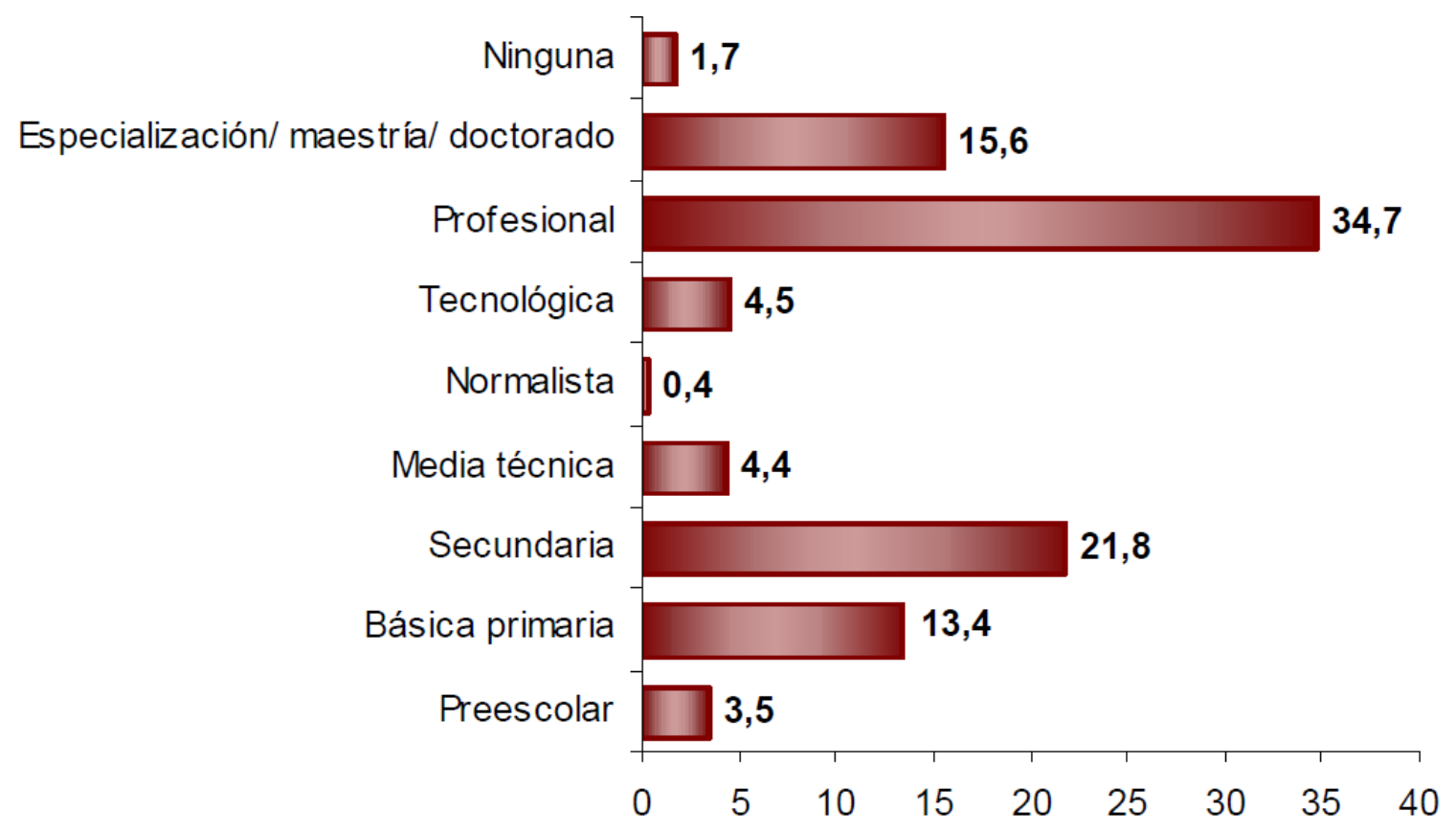

Ilustracion 6 Tabla de Medición de educación-Tomado del Boletín Dane año 2005

\section{Rango de Edades Localidad de Chapinero}

A continuación se anexa tabla donde se muestran el rango de edades con base en el censo realizo por el Dane en el año 2005. 


\begin{tabular}{|c|c|c|c|}
\hline Rango de edades & $\begin{array}{c}\text { Total Habitantes } \\
\text { Chapinero }\end{array}$ & Hombre & Mujer \\
\hline & 122089 & 54940 & 67149 \\
\hline 0 a 4 & 5988 & 3092 & 2896 \\
\hline 5 a 9 & 6096 & 3161 & 2935 \\
\hline 10 a 14 & 6310 & 3200 & 3110 \\
\hline 15 a 19 20 a 24 & 9252 & 4283 & 4969 \\
\hline 25 a 29 & 13683 & 6081 & 7602 \\
\hline 30 a 34 & 13513 & 6094 & 7419 \\
\hline 35 a 39 & 10843 & 5092 & 5751 \\
\hline 40 a 44 & 9067 & 4265 & 4802 \\
\hline 45 a 49 & 8884 & 4042 & 4842 \\
\hline 50 a 54 & 8411 & 3570 & 4841 \\
\hline 55 a 59 & 7416 & 3119 & 4297 \\
\hline 60 a 64 & 6219 & 2684 & 3535 \\
\hline Más de 65 años & 4637 & 2068 & 2569 \\
\hline d & 11770 & 4524 & 7246 \\
\hline
\end{tabular}

Tabla 7 Tabla rango de edades- Autoría Global Glamping

\section{Ruta de llegada a Global Glamping}

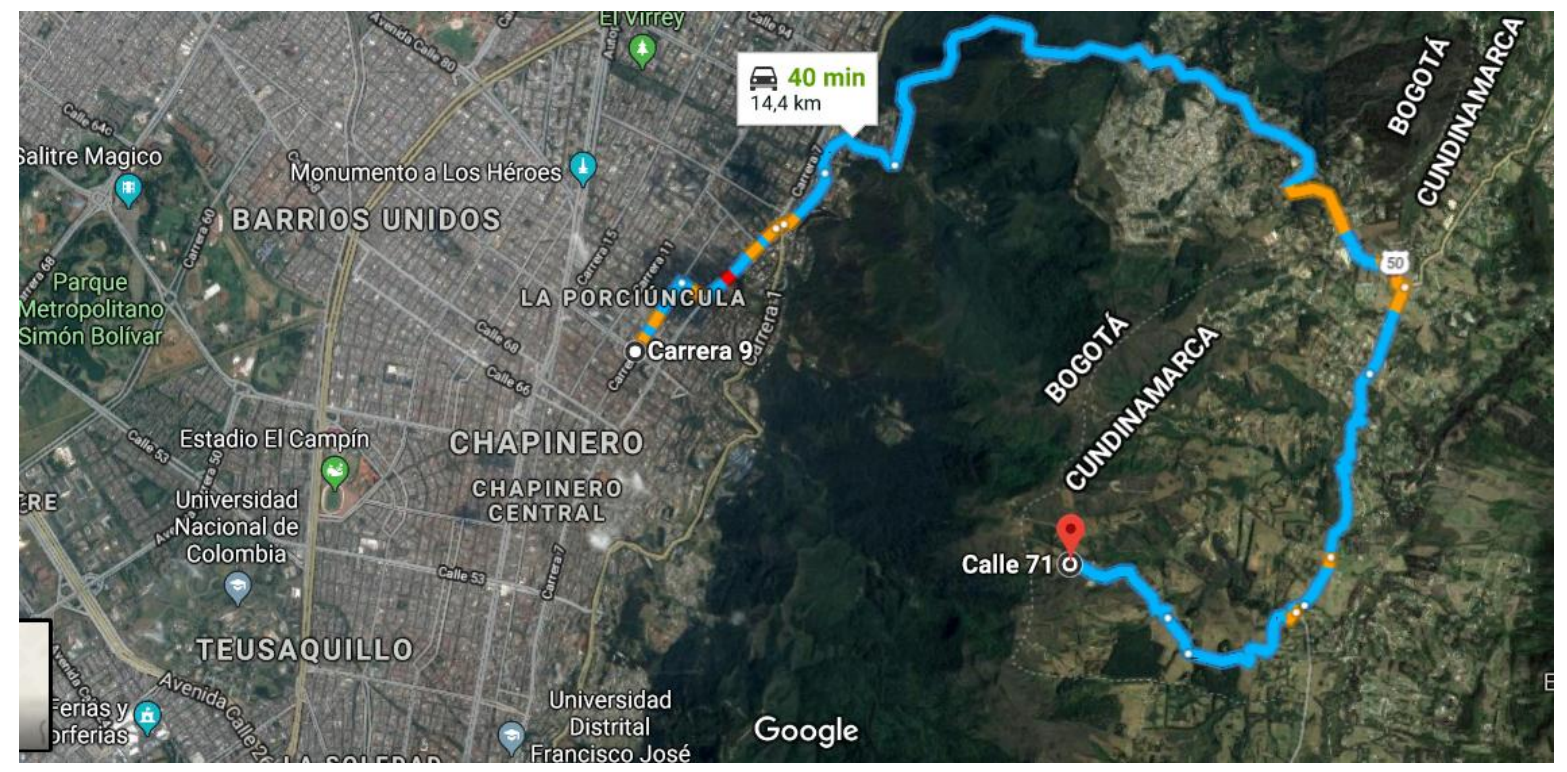

Ilustración 4: Ruta de llegada a Global Glamping desde Chapinero 
Con el fin de realizar una encuesta que resalten los gustos y preferencias de los habitantes de esta localidad, los cuales serán posteriormente de vital importancia para la toma de decisiones de Global Glamping, usaremos la siguiente fórmula de "Tamaño de Muestra”.

$$
n=\frac{N \times Z_{a}{ }^{2} \times p \times q}{d^{2} \times(N-1)+Z_{a}{ }^{2} \times p \times q}
$$

Ilustración 5: Formula para medir el Tamaño de la Población

En donde identificamos 5 variables, que una vez sean remplazadas y resuelta la formula obtendremos la cantidad exacta de personas a encuestar.

\begin{tabular}{|l|}
\hline \multicolumn{1}{|c|}{ Variables } \\
$\mathrm{Z}=$ nivel de confianza \\
$\mathrm{P}=$ probabilidad de éxito, o proporción esperada \\
$\mathrm{Q}=$ probabilidad de fracaso \\
$\mathrm{D}=$ precisión (Error máximo admisible en términos de proporción).
\end{tabular}

Tabla 2: tabla de Variables - formula "Tamaño de la Muestra"

Con base en la fórmula de la muestra, nos brinda la facilidad de identificar el número de encuestas que debe realizar Global Glamping para ver la aceptación de este servicio a los posibles clientes, tomaremos un riesgo de un $92 \%$ de confianza en los datos 
de la encuesta y un $8 \%$ de margen de error, la población objetivo de Global Glamping son todos los profesionales que estén interesados en realizar esta actividad, en la localidad de Chapinero el número de profesionales es del $50.3 \%$ el cual representa 61410 personas, el mínimo de encuestas que se deben realizar son de 120.

Una vez realizamos el correspondiente remplazo de variables obtenemos la siguiente información:

\begin{tabular}{|l|c|}
\hline \multicolumn{2}{|c|}{ Tamaño de la muestra } \\
\hline Tamaño de la población objetivo & $\mathbf{6 1 . 4 1 0}$ \\
\hline Nivel de confianza & $\mathbf{9 2 \%}$ \\
\hline Margen de Error & $\mathbf{8 \%}$ \\
\hline Total tamaño de muestra & $\mathbf{1 2 0}$ \\
\hline
\end{tabular}

Tabla 3 Muestra de Población Objetivo - Autoría Global Glamping

Ahora que se tiene identificada la población a la cual se le realizara la correspondiente encuesta, es necesario identificar cuáles serán aquellas características geográficas, demográficas, Psicológicas y Conductuales con las cuales contara este grupo de personas.

\section{- Perfil del Cliente Objetivo}

El perfil del cliente para Global Glamping se enfocará principalmente en personas que residen en Colombia, especialmente en la ciudad de Bogotá - Localidad Chapinero y sus alrededores, a continuación, se relacionan algunos datos de importancia para el mercado: 


\begin{tabular}{|c|c|}
\hline \multicolumn{2}{|c|}{ Perfil del Cliente Objetivo } \\
\hline Género: & - Hombre y Mujer \\
\hline Edad: & - $25-60$ años. \\
\hline Nacionalidad: & - Colombiano \\
\hline Nivel de Educación: & $\begin{array}{l}\text { - Profesional en Proceso en } \\
\text { adelante }\end{array}$ \\
\hline Nivel de Ingresos: & - Más de 4 SMLMV \\
\hline Estado Civil: & - Indiferente \\
\hline Intereses: & - Viajes \\
\hline \multirow[t]{4}{*}{ Aficiones } & - Deportes \\
\hline & - Viajar \\
\hline & - Animales \\
\hline & - Naturaleza \\
\hline & - Dinámica \\
\hline & - $\quad$ Tranquila \\
\hline & - Sociable \\
\hline & - $\quad$ Extrovertido \\
\hline Localización & - Todas las ciudades del país \\
\hline \multirow[t]{4}{*}{ Relaciones } & - Familia \\
\hline & - Amigos \\
\hline & - $\quad$ Pareja \\
\hline & - Grupos Laborales \\
\hline
\end{tabular}

Tabla 4 Caracteristicas del Cliente Objetivo - Autoria Global Glamping

A partil del perfil del cliente objetivo planteado anteriormente, se realizará a continuación un estudio de mercado con el fin de encontrar las oportunidades y estrategias que Global Glamping necesitará para responder con las necesidades del mercado y evaluar el impacto que este proyecto tendrá en la sociedad.

\section{- Resultados de la Encuesta}

Según la encuesta realizada a la muestra planteada, identificamos los siguientes resultados: 


\section{Cantidad de Población por Sexo}

\begin{tabular}{|c|c|}
\hline \multicolumn{2}{|c|}{ Discriminación por sexo - Población encuestada } \\
\hline Detalle & Cantidad \\
\hline Hombre & 87 \\
\hline Mujer & 64 \\
\hline Total & 151 \\
\hline
\end{tabular}

Tabla 5 Discriminación por sexo población encuestada - Autoría Global Glamping

\section{Ocupación de la Población}

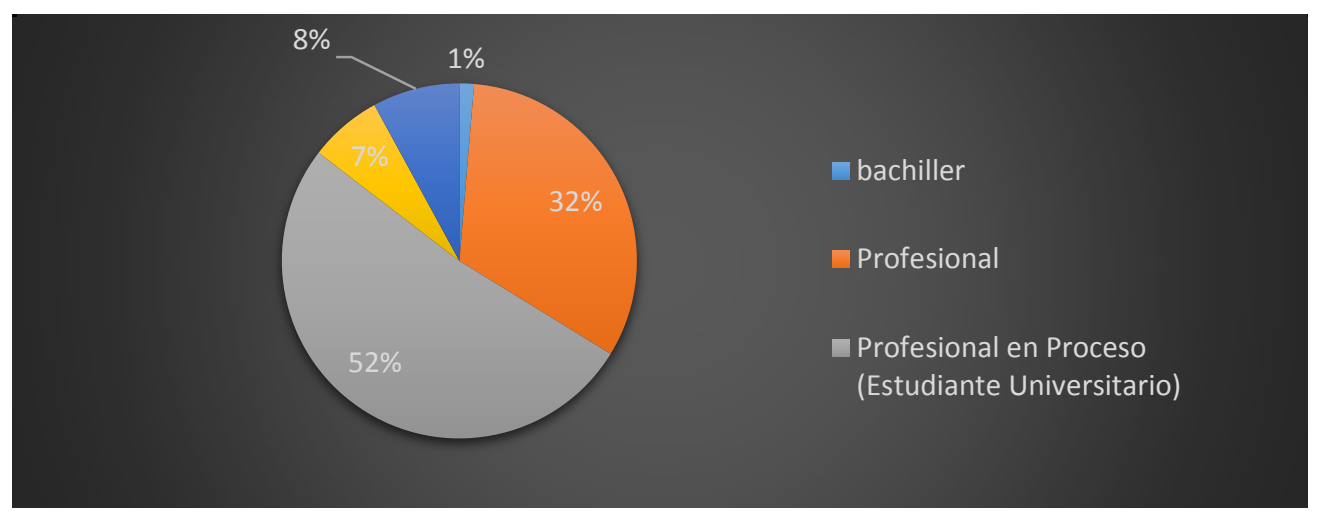

Ilustración 6 Discriminación porcentual de la Ocupación de los Encuestados - Autoría Global Glamping

\section{Edad de la Población}

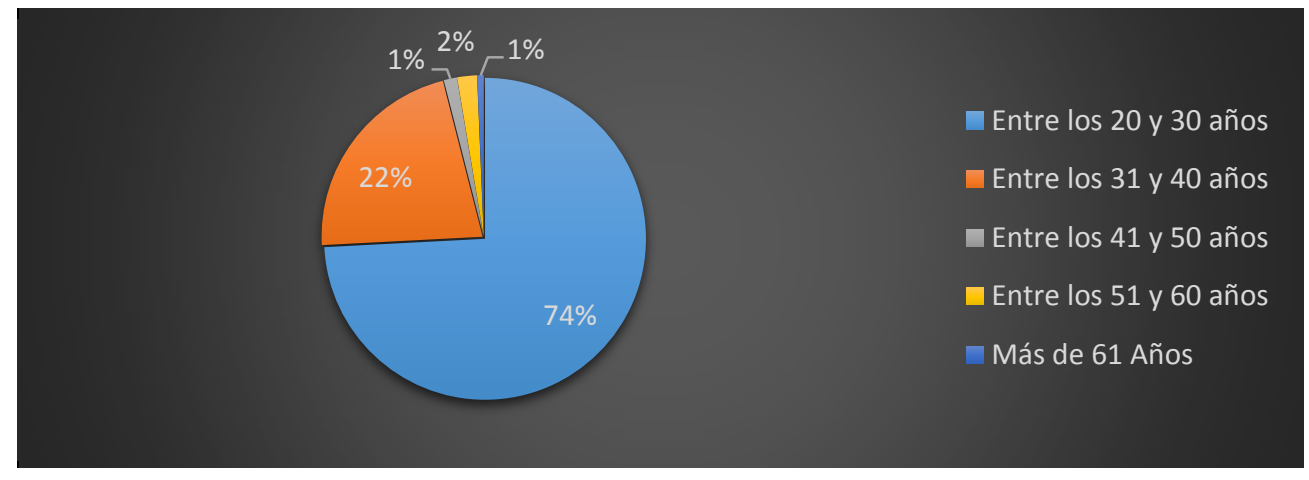

Ilustración 7 Discriminación porcentual de la Edad de los Encuestados - Autoría Global Glamping 


\section{Aceptación del Glamping como plan vacacional}

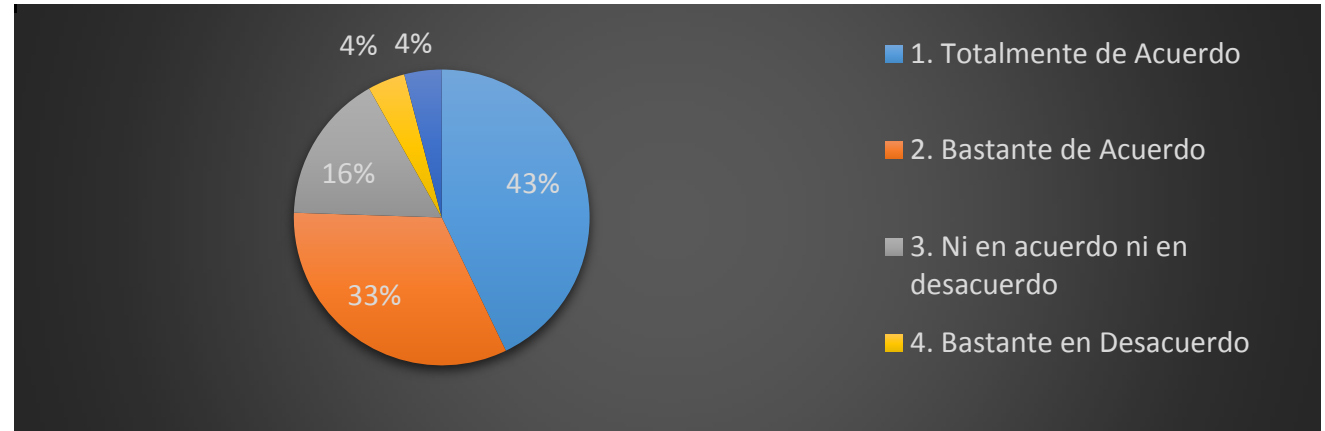

Ilustración 8 Discriminación porcentual de la aceptabilidad de Global Glamping en los encuestados - Autoría Global Glamping

\section{Tipo de Glamping}

\section{Eleccion de Glamping}

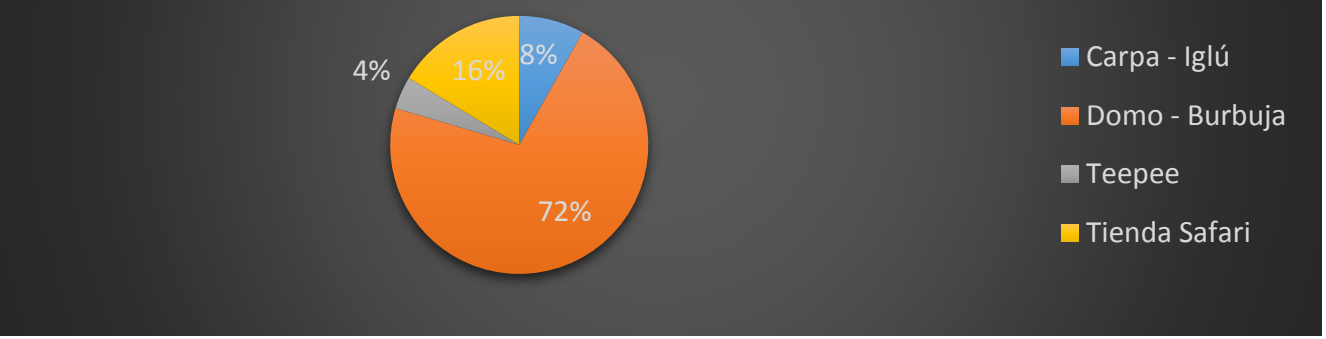

Ilustración 9 Discriminación porcentual de la elección de Glamping - Autoria Global Glamping

\section{Elección e acompañante}

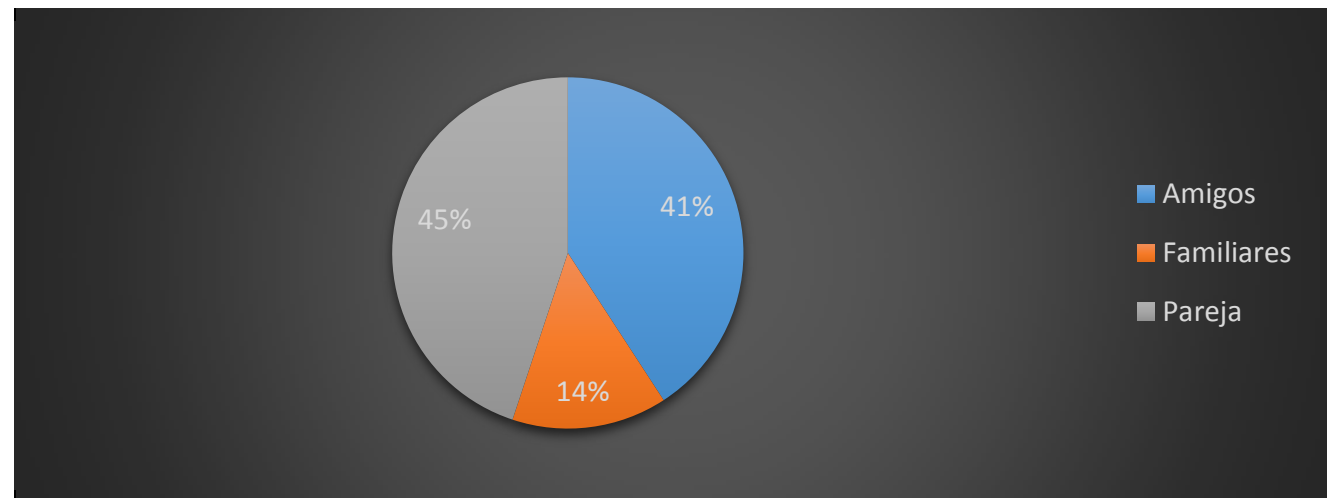

Ilustración 10 Discriminación porcentual de la elección de Acompañante según Encuestados - Autoria Global Glamping 


\section{Servicios Adicionales}

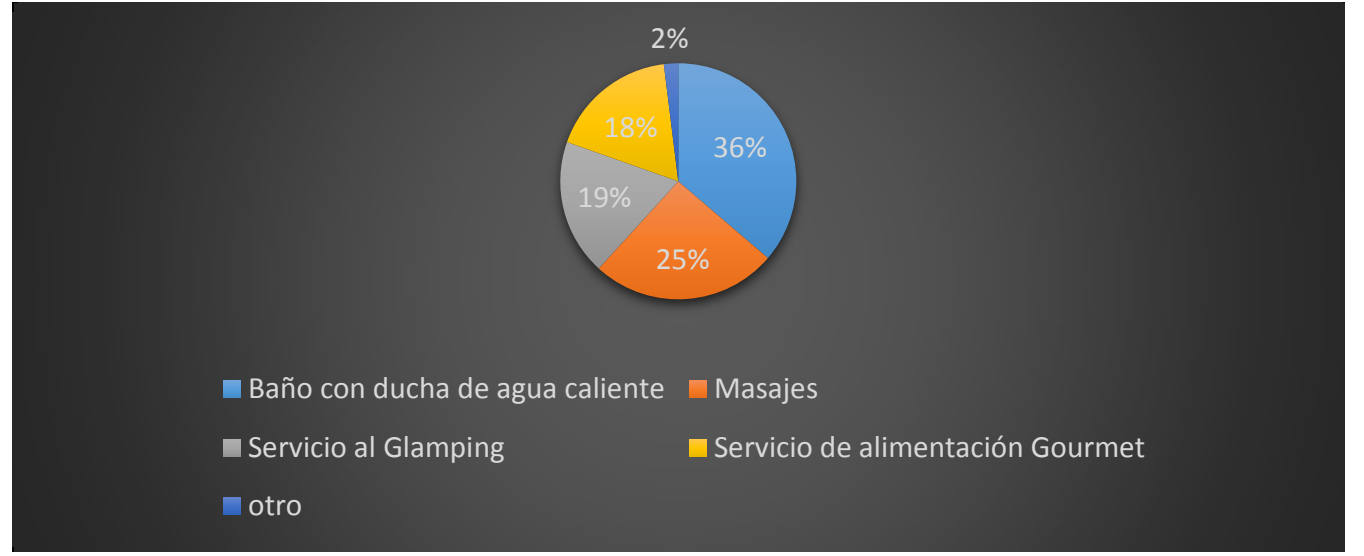

Ilustración 11 Discriminación porcentual al servicio necesario según Encuestados - Autoria Global Glamping

\section{Actividades Adicionales}

\begin{tabular}{l|c|} 
Detalle & Cantidad \\
\hline Fogatas Nocturnas & 36 \\
Cabalgatas & 31 \\
Rutas de Senderismo & 29 \\
Ciclo montañismo & 28 \\
Avistamiento de aves & 17 \\
\hline Total general & $\mathbf{1 4 1}$
\end{tabular}

Tabla 6 Discriminacion cuantitativa de mejor servicio esperado por los encuestados - Autoria Global Glamping

\section{Rango de Precios}

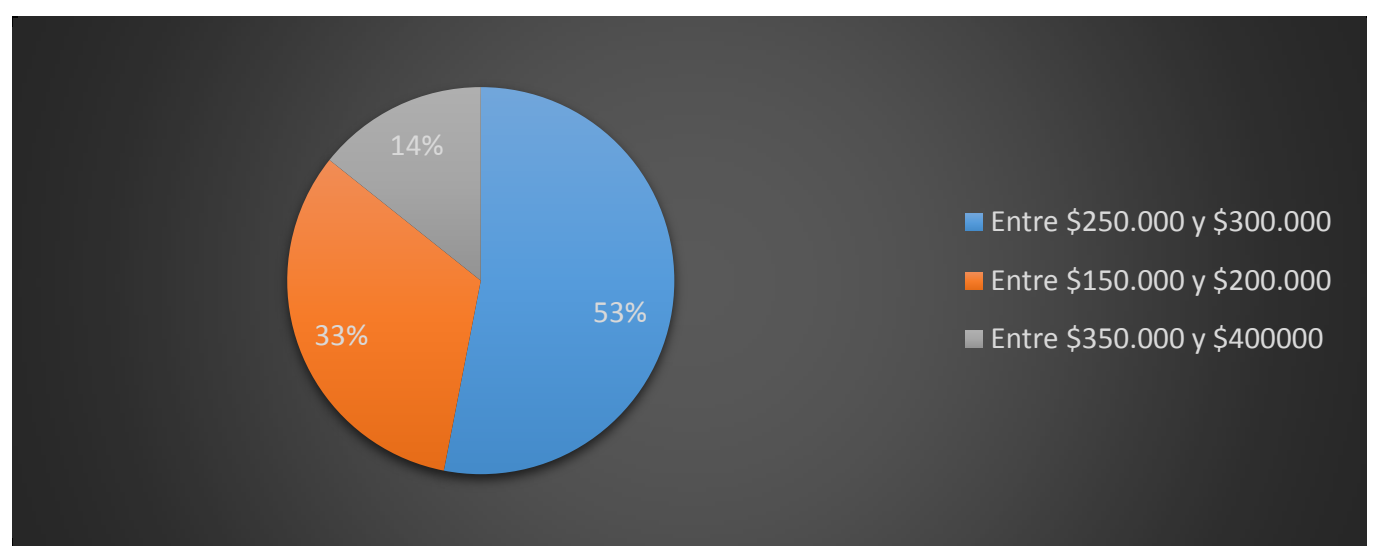

Ilustración 12 Discriminación porcentual según rango de precios sugerido por los encuestados - Autoria Global Glamping 


\section{- Análisis de Resultados}

Frente a la encuesta realizada anteriormente, se concluye que nuestros principales clientes son aquellas personas que se encuentran en un rango entre los $20 \mathrm{y}$ los 30 años, cuyo grado de escolaridad se varía entre "Profesional en proceso" y "Profesional" y que desee vivir esta experiencia con amigos y parejas en un Glamping en forma de Domo Geodésico (Burbuja).

Al realizar la encuesta se ve un alto grado de curiosidad e interés por parte de los encuestados por conocer más acerca del concepto de Glamping, además de ello, todos están de acuerdo con la importancia del cuidado hacia el medio ambiente y prestan un alto grado de atracción por tomar este destino turístico dentro de sus planes vacacionales, con la finalidad de salir de lo cotidiano y conectarse más con la naturaleza, buscando vivir una experiencia natural diferente a las que cotidianamente realizan.

Se analiza en los encuestados la amplia diferencia entre el precio y el valor que estos tienen a la hora de tomar un servicio, en donde la mayoría difiere en la importancia de la atención al cliente y la calidad del servicio, siendo estos, aspectos por los cuales pagarían un valor que oscila entre los $\$ 250.000$ y los $\$ 300.000$ pesos, rango que se encuentra dentro de los precios del mercado y es asequible para los clientes y para el crecimiento inicial del negocio.

\section{Plan de Mercadeo}

\section{- Análisis de la Situación}

Global Glamping está ubicado en el sector terciario de la economía, el cual, según (Republica S. G., 2015) lo define como aquel sector que no produce ningún tipo de 
mercancía pero que es necesario para el funcionamiento de la economía, de igual manera, es considerado como un sector no productivo, sin embargo, contribuye con la transformación de ingreso nacional, no obstante, dentro de este sector se ve reflejado el sector de naturaleza en el cual se ubica de manera específica a Global Glamping en el subsector eco turístico, que según El Ministerio de Industria, Comercio y Turismo (COMERCIO, s.f), lo define como: “un conjunto de fenómenos causados por impactos socioeconómicos, culturales y ambientales generados por el desplazamiento y la permanencia temporal de personas que invierten parte de su tiempo en recreación y vacaciones, visitando lugares que ofrecen bienes y servicios en pro del conocimiento y el ocio.” y que adicionalmente, cuenta con una serie de características de las cuales podemos destacar: se desarrolla en lugares naturales con un interés particular, por ejemplo: montañas, busca realizar actividades sin alterar el equilibrio de la naturaleza, las actividades que se practican en este sub-sector del sector turístico de naturaleza se practican en pareja o en grupo, genera la unificación de la industria turística con la ecológica, que involucra la ética en sus actividades preservando el bienestar de la naturaleza y el desarrollo sostenible y que especialmente promueve el respeto absoluto por la cultura del país anfitrión

El ecoturismo es una actividad que está relacionada 100\% con el entorno. A comparación del turismo tradicional, en el cual, los visitantes se encuentran más interesados en sus experiencias personales y en disfrutar de una máxima comodidad durante su estadía en los días de viaje, esta actividad busca que el viajero contemple otros factores diferentes como lo es: La sostenibilidad ecológica, La responsabilidad social y la conciencia cultural. (Montes, 2006). 


\section{- Antecedentes del Sector Turístico}

Basados en el estudio realizado por (Ministerio de Comercio, 2017), los resultados del sector turístico para el año 2016 fueron extraordinarios todo por el trabajo y la proyección realizada desde el 2010, año en el cual, las primeras inversiones el sector del turismo se vieron evidenciadas, con base en ello, se resaltan una serie de puntos que marcaron la historia del sector turístico desde el año 2010 hasta el año 2015, algunas de estas son: El número de turistas internacionales aumento un 70\%, El empleo aumentó un 17\%, La inversión extranjera aumento un 700\%, Las divisas aumentaron un 52\%, Incrementó en el número de los prestadores de servicios.

Adicionalmente según datos claves para la industria del turismo expuestos por (Gobierno, 2017), de los cuales podemos encontrar un aumento formal en la industria turística desde el año 2010 al 2016 de un 76,4\% y del 2015 al 2016 de un 11,5\%, además aumentaron en 370.000 nuevos puestos de trabajo entre el 2010 y el 2016 y para el año 2017 por concepto de la actividad de avistamiento de aves, se tiene dato de alrededor de 300 mil avisadores con una inversión de \$1.067.225.896 millones de creación de ruta turística, capacitación, guianza, bilingüismo e infraestructura.

La injerencia del turismo en el PIB se mantiene y viene creciendo más del 2,6\%. Según (CITUR, 2017), analizando las estadísticas nacionales económicas del crecimiento del PIB a lo largo del periodo 2010 al 2016, se puede evidenciar que con el pasar de los años ha venido teniendo un incrementando continuo, además de ello, se observa la participación que tiene la industria hotelera que al igual que el PIB esta en constante crecimiento. 


\begin{tabular}{|c|c|c|c|c|c|c|c|}
\hline & 2010 & 2011 & 2012 & 2013 & 2014 & 2015 & 2016 \\
\hline Hoteles y restaurantes & 11,963 & 12,447 & 12,916 & 13,643 & 14,323 & 15,209 & 15,445 \\
\hline$\%$ de Crecimiento anual & $5 \%$ & $4 \%$ & $4 \%$ & $5 \%$ & $5 \%$ & $6 \%$ & $2 \%$ \\
\hline Producto Interno Bruto & 424,599 & 452,578 & 470,880 & 493,831 & 515,528 & 531,262 & 541,675 \\
\hline$\%$ de Crecimiento anual & $4 \%$ & $6 \%$ & $4 \%$ & $5 \%$ & $4 \%$ & $3 \%$ & $2 \%$ \\
\hline
\end{tabular}

Ilustración 13 Crecimiento porcentual del PIB 2010 - 2016 - Autoria CITUR 2016

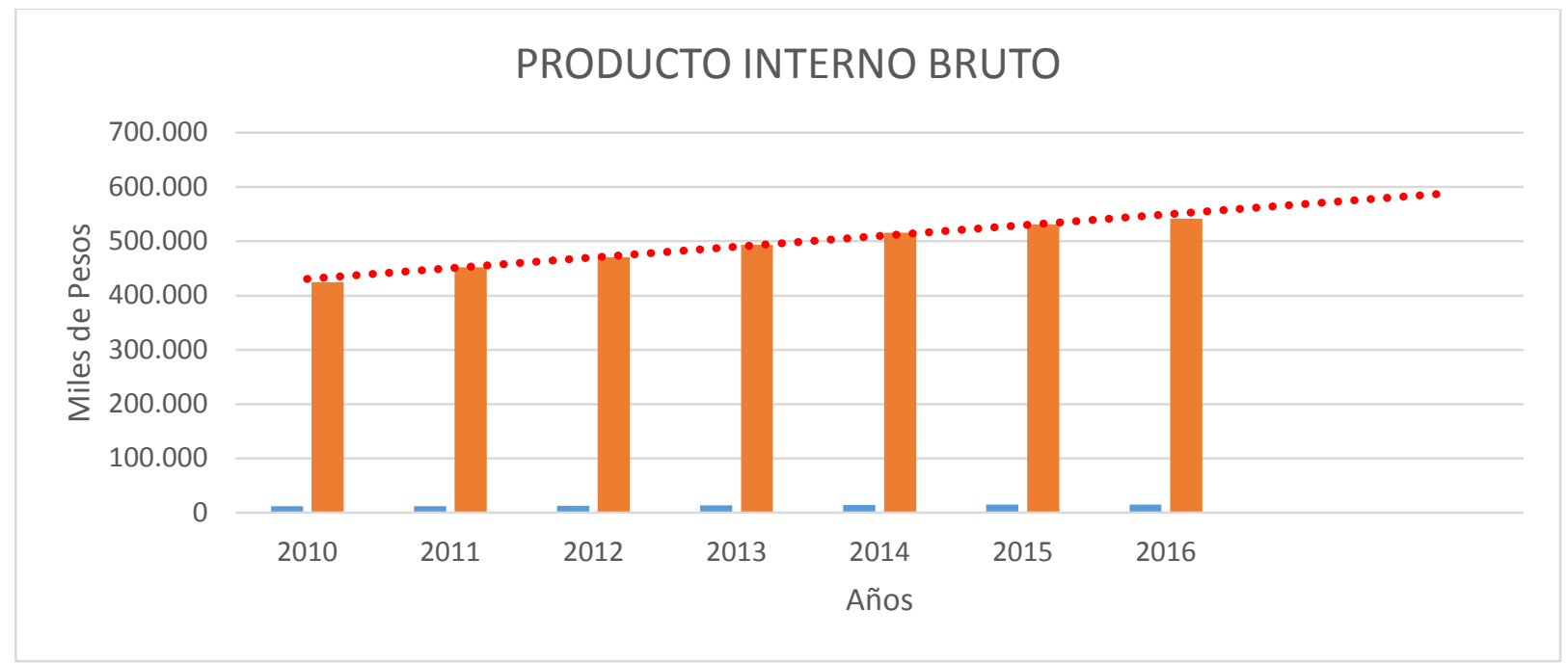

Ilustración 14 Crecimiento del PIB 2010 - 2016 - Autoria CITUR 2016

Con base en el estudio realizado por (PTP, 2013), algunos aspectos que caben resaltar según estudio del ciclo de vida de los subproductos del Turismo de Naturaleza, se encontró que específicamente el eco turístico se encuentra dirigido a un sector de personas cultas, maduras y enfocadas con el medio ambiente, tanto así que hablando a nivel global existen alrededor de 64 millones de personas al año que realizan actividades de ecoturismo. 


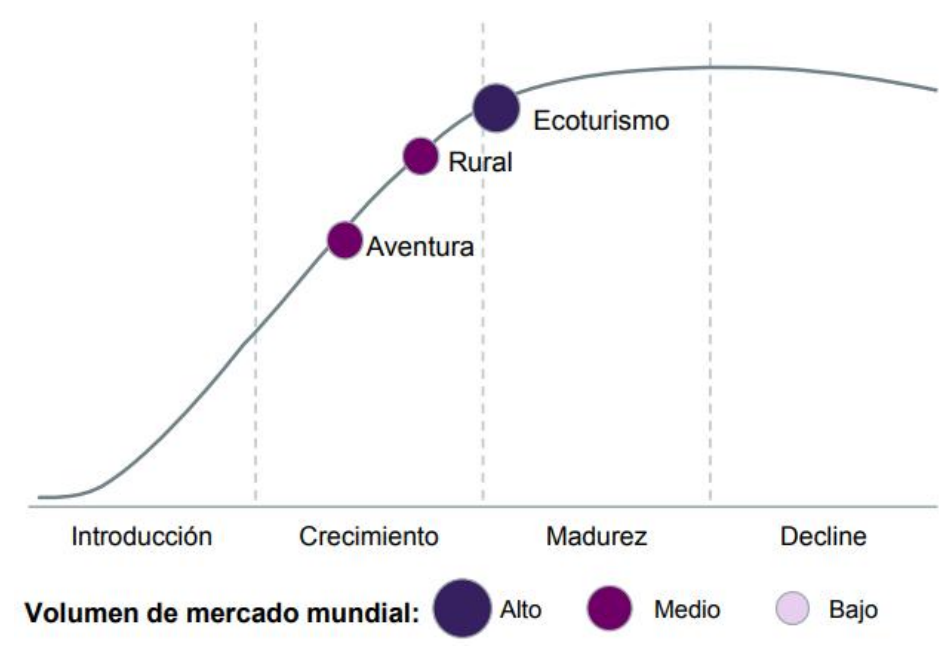

Ilustración 15 Ciclo de vida sub-productos del Turismo de Naturaleza-Basado en: Informe PTP 2013

\section{- Panorama del sector Eco-turístico para el año 2017 - 2018}

Tomando como referencia el artículo "Turismo Sostenible, vital para las regiones: Ministra de Comercio" presentado por el Ministerio de Comercio, Industria y Turismo (Ministerio de Comercio, 2017), El sector turístico es de los sectores que más le deja divisas al país, tanto así, que antes de que se presentara la firma del tratado de paz el sector mostraba crecimientos anuales ascendentes, María Claudia Lacouture, Ministra de Comercio Industria y Turismo afirma que se espera un crecimiento del 10\% en términos de turismo para el 2018, estamos hablando que en este preciso momento su crecimiento en recaudo de divisas está por encima de productos como las flores, el banano y el carbón. De antemano se espera una proyección para el año 2018 de un ingreso al país 5’400.000 turistas y aproximadamente unos 6000 millones de dólares, partiendo del hecho de que un porcentaje de este recaudo es esperado en gran medida por el sector de naturaleza. Para primer semestre del año 2017, han llegado 2'921.818 visitantes del exterior, frente a 1'996.587 que arribaron el año pasado, de lo cual, se refleja un aumento del 46,3\% en comparación con el año 2016. El turismo es un gran generador de desarrollo y equidad, por 
esta razón, se apuesta a la creación de Global Glamping como un engrane en ese crecimiento exponencial del sector eco-turístico del país, tras las consecuencias positiva, las mejoras que el país ha venido implementando anteriormente y las proyecciones que se tienen para los futuros años

\section{- Aspectos Sociales}

Global Glamping centra la promoción de su servicio en las personas radicadas en Bogotá, y aquellas personas que a nivel nacional visitan la ciudad independiente el motivo pero que dentro de su estadía se encuentre la opción de realizar excursiones, camping o planes vinculados con la naturaleza, según un estudio realizado en Febrero del 2016 por el Departamento Administrativo Nacional de Estadística (DANE, 2016), tomando como objetivo conocer el gasto interno en turismo para el periodo agosto 2014 a Julio 2015 de los Colombianos, determinó que Bogotá está dentro de las 24 ciudades más visitadas turísticamente con un promedio de 1’126.000 visitantes en la ciudad, teniendo una participación de visitas 16,9\% a comparación con las demás, adicionalmente, se concluyó que de esas personas que visitaban la ciudad el 7,6\% era por concepto de trabajo o negocios, el 45,9\% era por recreación o vacaciones, el 42,2\% era por visita a parientes o amigos, y otros motivos lo ocupaba el 3,3\% como lo muestra la siguiente imagen: 


\section{Distribucion porcentual del motivo de visita a Bogota}

Trabajo o negocios

Recreación-vacaciones

IVisita a parientes o amigos

IOtro

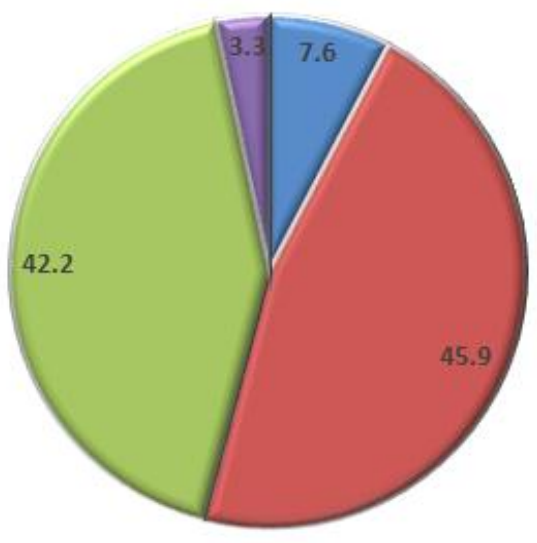

Ilustración 16 Distribución Porcentual de Motivos de Visitas Bogotá - Autoria Global Glamping

La oportunidad de negocio está reflejada en el porcentaje de personas que vienen a Bogotá por concepto de recreación - vacaciones y visita a parientes y amigos, de igual manera, la presente investigación refleja el promedio de personas que en el lapso de tiempo que estuvieron en la ciudad realizaron algún tipo de excursión, estamos hablando de un total de 787.000 personas, las cuales según su motivo de visita a la ciudad están discriminadas de la siguiente manera $17,4 \%$ era por trabajo o negocios, el $54,6 \%$ era por recreación o vacaciones, el 20,9\% era por visita a parientes o amigos, y otros motivos lo ocupaba el 7,1\% como lo muestra la siguiente imagen: 


\section{Excursión por motivo de viaje a Bogotá}

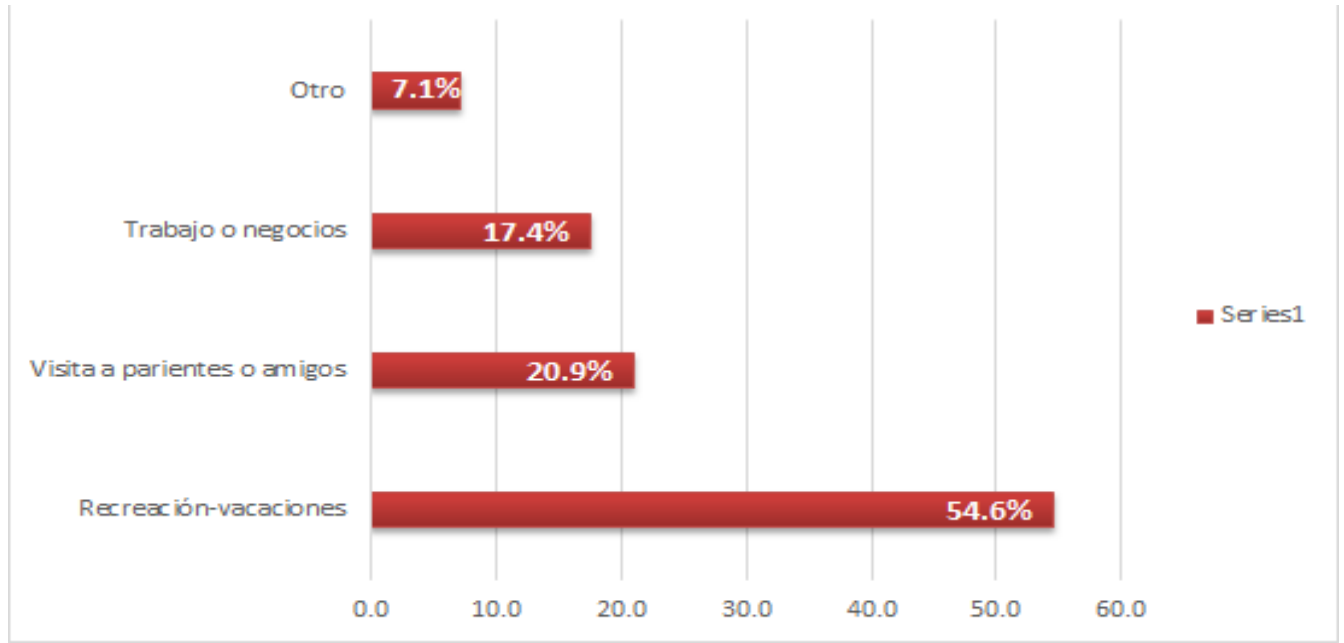

Ilustración 17 Excursión por concepto de Motivo de Viaje - Bogotá - Autoria Global Glamping

Analizando la anterior información del sector turístico en Bogotá, se determina que existen posibilidades de crecimiento en términos de creación de empresas que presten servicios ecoturísticos con la intención de que las personas interactúen de una manera mucho más cómoda con la naturaleza y adicionalmente, que se genere en ellas un impacto positivo frente al cuidado y la preservación del medio ambiente.

Según (MINCIT, 2017) en su Boletín Mensual de Turismo del mes de noviembre 2017, el cual presenta los principales indicadores de turismo en el transcurso del año, se puede observar los siguientes puntos cruciales que hacen la implementación de Global Glamping un negocio viable.

\begin{tabular}{|c|c|c|c|c|c|}
\hline \multirow[b]{2}{*}{ TIP } & \multicolumn{4}{|c|}{ AÑO } & \multirow[b]{2}{*}{ VAR (\%) } \\
\hline & & 2016 & & 2017 & \\
\hline Extranjeros no residentes & $\$$ & 2.342 .561 & $\$$ & 2.887 .259 & $19 \%$ \\
\hline Colombianos residentes en exterior & $\$$ & 586.029 & $\$$ & 638.454 & $8,2 \%$ \\
\hline Cruceros Internacionales & $\$$ & 247.267 & $\$$ & 295.122 & $16 \%$ \\
\hline Transfronterizos & $\$$ & 1.352 .497 & $\$$ & 1.960 .340 & $31 \%$ \\
\hline Total & & 4.528.354 & & 5.781.175 & $22 \%$ \\
\hline
\end{tabular}

Tabla 7 Receptivo de viajeros en el transcurso del año 2017 - Basado en: MINCIT 2017 
Se puede observar el incremento porcentual de viajeros que ingresaron a Colombia en el año 2017 a comparación del 2016 lo cual es favorable para Colombia pese a que son una diferencia favorable de 1.252.821 personas de las cuales se registra un crecimiento del 18,31\% en la ciudad de Bogotá, según lo muestra en siguiente cuadro.

\begin{tabular}{l|l|l|l|}
\hline Departamento & $\mathbf{2 0 1 6}$ & $\mathbf{2 0 1 7}$ & $\mathbf{\%}$ \\
\hline Bogotá & 1.103 .214 & 1.305 .228 & $18,31 \%$ \\
\hline
\end{tabular}

Según (MINCIT, 2017) el acumulado de personas en el rango de Enero a Agosto del 2017 que genero una visita a algún parque Natural hace referencia a un total de 1.204.894 personas, el cual, si se realiza la comparación con el resultado del año 2016 se concluye que se generó un aumento de visitas en un 10,1\% siendo igualmente agosto uno de los meses donde su aumento de vistas en todo el año es de los mejores.

\begin{tabular}{l|c|c|c|}
\hline Rango de Meses & $\mathbf{2 0 1 6}$ & $\mathbf{2 0 1 7}$ & $\mathbf{\%}$ (VAR) \\
\hline ENE - AGOST & 1.095 .478 & 1.204 .894 & $10,00 \%$ \\
\hline
\end{tabular}

\begin{tabular}{|l|c|c|c|}
\hline \multicolumn{1}{|c|}{ Mes de mejores Visitas } & $\mathbf{2 0 1 6}$ & $\mathbf{2 0 1 7}$ & $\mathbf{\%}$ (VAR) \\
\hline AGOST & 119.003 & 142.729 & $19,90 \%$ \\
\hline Tabla 10 Viajeros segun mejor mes de Visitas & $2016-2017$ - Basado en: MINCIT 2017
\end{tabular}

A partir de los datos brindados por Migración Colombia, (MINCIT, 2017) el cual, hace relación al motivo de viajes de las personas hasta el mes de Noviembre 2017 y comparándolo con el mismo transcurso de tiempo pero del año 2016, obtenemos la siguiente información: 


\begin{tabular}{|l|r|r|r|r|r|r|}
\cline { 2 - 8 } \multicolumn{1}{c|}{} & \multicolumn{3}{c|}{ Noviembre } & \multicolumn{2}{c|}{ Enero a Noviembre } \\
\hline & $\mathbf{2 0 1 6}$ & \multicolumn{1}{c|}{$\mathbf{2 0 1 7}$} & \multicolumn{1}{c|}{$\%$} & \multicolumn{1}{c|}{$\mathbf{2 0 1 6}$} & \multicolumn{1}{c|}{$\mathbf{2 0 1 7}$} & \multicolumn{1}{c|}{$\%$} \\
\hline Vacaciones, recreo y ocio & 167.674 & 245.243 & $46,30 \%$ & 1.662 .276 & 2.248 .657 & $35,30 \%$ \\
\hline Negocios y motivos profesionales & 38.785 & 41.065 & $5,90 \%$ & 390.002 & 394.241 & $1,10 \%$ \\
\hline Otros motivos & 15.272 & 16.944 & $10,90 \%$ & 216.517 & 167.124 & $-22,80 \%$ \\
\hline Educación y formación & 5.760 & 5.701 & $-1,00 \%$ & 55.905 & 55.868 & $-0,10 \%$ \\
\hline Salud y atención médica & 1.329 & 1.847 & $39,00 \%$ & 13.323 & 16.425 & $23,30 \%$ \\
\hline Tránsito & 205 & 238 & $16,10 \%$ & 3.058 & 1.958 & $-36,00 \%$ \\
\hline Religión y peregrinaciones & 106 & 117 & $10,40 \%$ & 1.480 & 2.986 & $101,80 \%$ \\
\hline Total general & $\mathbf{2 2 9 . 1 3 1}$ & $\mathbf{3 1 1 . 1 5 5}$ & $\mathbf{3 5 , 8 0 \%}$ & $\mathbf{2 . 3 4 2 . 5 6 1}$ & $\mathbf{2 . 8 8 7 . 2 5 9}$ & $\mathbf{2 3 , 3 0 \%}$ \\
\hline
\end{tabular}

Tabla 11 Motivo de Vacaciones 2016 - 2017 - Basado en: MINCIT 2017

En este cuadro se observa el incremento porcentual que tuvo el año 2017 a

comparación del 2016, el cual se registra en 23,3\% el total del crecimiento de Enero a

Noviembre en los viajes hacia Colombia, donde su principal motivo de viaje sigue siendo

"Vacaciones, recreo y Ocio" al igual que lo fue en el año 2016, en este caso se ve reflejado

un incremento del 35,3\% en este rubro que para Global Glamping es el de mayor interés

para la promoción de sus servicios.

Abarcando otro punto de vista se prospecta que los principales clientes sean quienes se encuentren en el área de Bogotá y en la zona nacional del territorio Colombiano, no obstante, no se deja de lado la oportunidad de negocio que se abre frente a la llegada de los extranjeros a la ciudad. Para tener una mejor estadística de esto, El Centro de Información Turística de Colombia (CITUR, 2017), nos muestra la llegada de visitantes extranjeros no residentes por departamentos desde el 2010 al 2017, cabe aclarar que para este caso se tomará la información de extranjeros que hayan llegado ya sea a la ciudad de Bogotá o directamente a Cundinamarca.

\begin{tabular}{|l|r|r|r|r|r|r|r|r|}
\hline \multicolumn{1}{|c|}{ LUGAR } & \multicolumn{1}{c|}{$\mathbf{2 0 1 0}$} & \multicolumn{1}{c|}{$\mathbf{2 0 1 1}$} & \multicolumn{1}{c|}{$\mathbf{2 0 1 2}$} & \multicolumn{1}{c|}{$\mathbf{2 0 1 3}$} & \multicolumn{1}{c|}{$\mathbf{2 0 1 4}$} & \multicolumn{1}{c|}{$\mathbf{2 0 1 5}$} & $\mathbf{2 0 1 6}$ & $\mathbf{2 0 1 7}$ \\
\hline BOGOTA & 701978 & 797355 & 826591 & 888852 & 1012822 & 1146405 & 1211184 & 767109 \\
\hline CUNDINAMARCA & 4812 & 5629 & 5796 & 6406 & 8074 & 10422 & 12645 & 8381 \\
\hline TOTAL GENERAL & 706790 & 802984 & 832387 & 895258 & 1020896 & 1146415543 & 1184779754 & 775490 \\
\hline
\end{tabular}




\section{Llegada de visitantes extranjeros no residentes en Bogotá y Cundinamarca desde el} 2010 al 2017

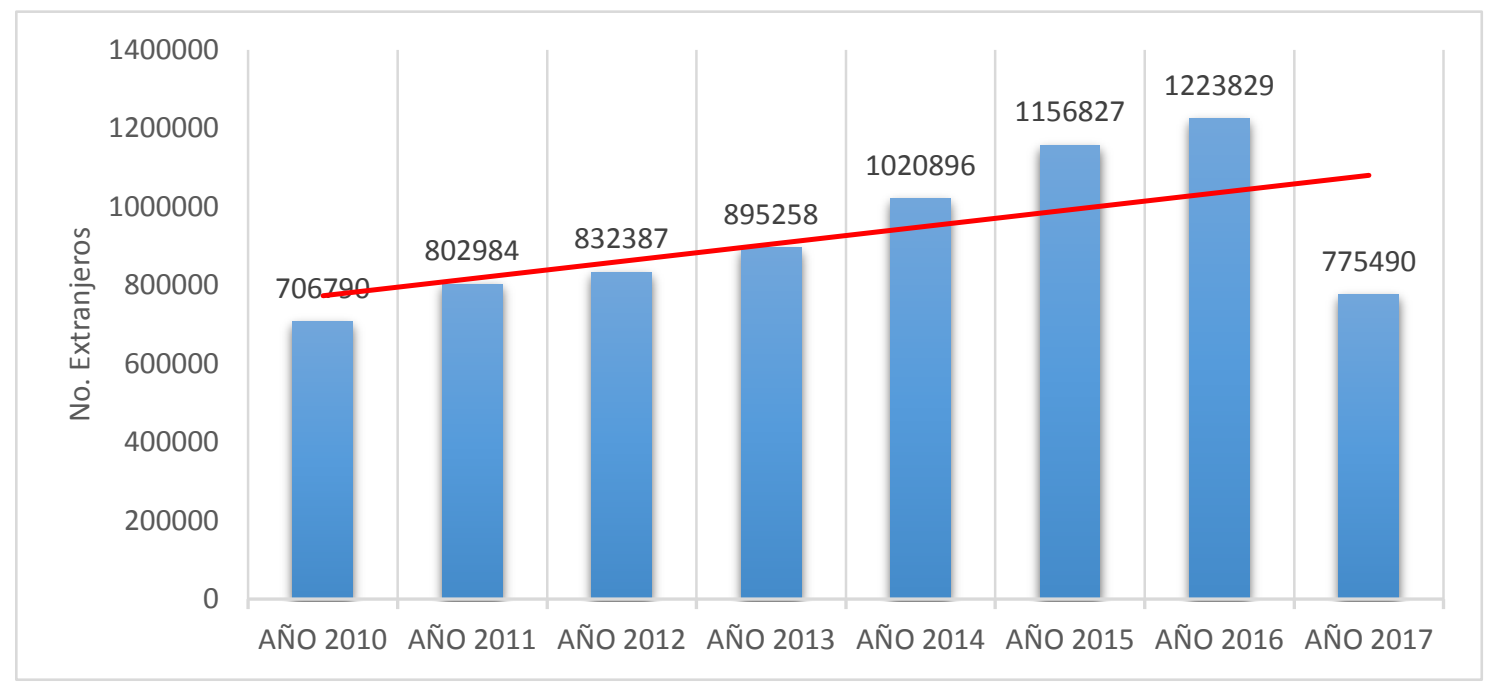

Ilustración 18 Llegada de Visitantes Extranjeros No Residentes en Bogotá - Basado en: CITUR 2017

Se observa que la posición en la que se encuentra Bogotá y Cundinamarca en términos de visitas de extranjeros no residentes en este momento, supera el $50 \%$ a comparación del año anterior, pese a esto, se cuenta con un amplio nivel mercado potencial con los cuales se podría implementar estrategias de mercado llamativas y buscar alianzas para aumentar el número de personas que demanden a vivir una experiencia totalmente diferente y deseen conocer la cultura de la región y del país.

\section{- Identificación de la Demanda}

Para identificar una buena estrategia uno de los aspectos más importantes para analizar es la previsión de la demanda, ya que frente a esta podemos obtener información suficiente para tomar decisiones, poder planificar las operaciones, proyectar ventas y medir el cumplimiento de los objetivos. 
Teniendo claro los diferentes tipos de demandas que existen para el Marketing, de los cuales podemos resaltar: Demanda Negativa, Cero Demanda, Demanda Latente, Demanda Irregular, Demanda Plena y Sobredemanda, se identificó que el que más le compete a Global Glamping para la implantación de sus estrategias es la Demanda Irregular, en la cual, se encuentra arraigada el patrón de la demanda con factores externos como los ciclos estacionales o fluctuaciones económicas que se presentan en un corto plazo, para este caso tenemos como principal amenaza la temporada climática del invierno puesto a que es un elemento que disminuirá de manera significativa la demanda para Global Glamping.

Como potencial estrategia pondremos el invierno a nuestro favor generando diversos planes para aquella temporada de lluvias, en donde las personas cuenten con lugares calidos, amplia variedad de comida, y actividades relajantes para que el clima no afecte la oportunidad de pasar una experiencia nueva con su acompañante.

Adicionalmente, como se ha expuesto anteriormente es de vital importancia la alianza con organizaciones buscando así diferentes contratos que sean útiles generando un ingreso fijo al negocio en un periodo de tiempo determinado.

Con el fin de identificar un poco más a fondo el entorno en el que se rodea Global Glamping y en pro de generar crecimiento y posicionamiento del negocio, analizaremos nuestra competencia directa, y sustituta identificando diferentes aspectos representativos. 


\section{- Análisis de la Competencia}

Buscando encontrar aquellas estrategias que son de vital importancia para el crecimiento de la compañía, se encontró una serie de organizaciones que presentan productos tanto similares como sustitutos a los de Global Glamping, a las cuales, se les centralizó la información en 4 aspectos importantes a evaluar: ubicación, descripción del negocio, precio, y actividades que realiza, a continuación se presenta con detalle las organizaciones para su posterior análisis:

Competencia Directa

\begin{tabular}{|c|c|c|c|c|}
\hline $\begin{array}{c}\text { Nombre de la } \\
\text { empresa }\end{array}$ & Ubicación & Descripción & $\begin{array}{c}\begin{array}{c}\text { Precio } \\
\text { por } \\
\text { persona } \\
\text { (rango) }\end{array} \\
\end{array}$ & Actividades \\
\hline $\begin{array}{l}\text { Glamping } \\
\text { Colombia }\end{array}$ & $\begin{array}{l}\text { Glamping Colombia } \\
\text { está ubicado en el } \\
\text { municipio de } \\
\text { Guatavita en la vereda } \\
\text { Tomine de Indios. }\end{array}$ & $\begin{array}{l}\text { Glamping Colombia presta } \\
\text { un servicio personalizado } \\
\text { cuenta con domos donde se } \\
\text { podrán hospedar los } \\
\text { turistas, las personas podrán } \\
\text { disfrutar de la naturaleza y } \\
\text { al mismo tiempo estar en un } \\
\text { lugar cómodo }\end{array}$ & $\$ 291.000$ & $\begin{array}{l}\text { Parapente, } \\
\text { Recorrido en } \\
\text { velero } \\
\text { Cabalgatas } \\
\text { Caminatas }\end{array}$ \\
\hline $\begin{array}{l}\text { Niddo } \\
\text { NIDDO }\end{array}$ & $\begin{array}{l}\text { Niddo está ubicada vía } \\
\text { a Suesca en el } \\
\text { Kilómetro } 6 .\end{array}$ & $\begin{array}{l}\text { Cuenta con habitaciones } \\
\text { que están integradas al } \\
\text { medio ambiente, la cual la } \\
\text { hacen más rusticas y } \\
\text { agradable para los turistas a } \\
\text { la hora de hospedarse en } \\
\text { una cabaña de estas. }\end{array}$ & $\$ 200.000$ & $\begin{array}{l}\text { Escalada en } \\
\text { roca } \\
\text { Espeleología } \\
\text { yoga } \\
\text { Caminatas } \\
\text { Cabalgatas } \\
\text { Telas } \\
\text { acrobáticas }\end{array}$ \\
\hline $\begin{array}{c}\text { Bambu } \\
\text { Glamping City } \\
\text { House }\end{array}$ & $\begin{array}{l}\text { Bambu Glamping City } \\
\text { House, es un Hostal } \\
\text { Ubicado en Medellín, }\end{array}$ & $\begin{array}{l}\text { Cuenta con dos Glamping } \\
\text { con capacidad para dos } \\
\text { personas, es un lugar } \\
\text { agradable ya que está }\end{array}$ & $\$ 49.708$ & $\begin{array}{l}\text { Caminatas } \\
\text { cortas } \\
\text { Disfrutar una } \\
\text { noche }\end{array}$ \\
\hline
\end{tabular}




\begin{tabular}{|c|c|c|c|c|}
\hline$y=x$ & & $\begin{array}{l}\text { rodeado de arboles y jardín } \\
\text { espectacular, }\end{array}$ & & $\begin{array}{l}\text { acompañado } \\
\text { de fogatas }\end{array}$ \\
\hline $\begin{array}{c}\text { Bethel Bio } \\
\text { Luxury Hotel }\end{array}$ & $\begin{array}{l}\text { El Bethel Bio Luxury } \\
\text { Hotel, Se encuentra } \\
\text { ubicado en el Desierto } \\
\text { de la Tatacoa, }\end{array}$ & $\begin{array}{l}\text { Cuenta con un sitio } \\
\text { espectacular, tiene } \\
\text { diferentes tipos de tipis, } \\
\text { adicionalmente tiene } \\
\text { cabañas. }\end{array}$ & $\$ 439.000$ & $\begin{array}{l}\text { Tour por el } \\
\text { desierto de la } \\
\text { tatacoa en } \\
\text { cuatrimotor. } \\
\text { Caminatas. } \\
\text { Tour en } \\
\text { Helicóptero. } \\
\text { Masaje } \\
\text { relajante. } \\
\text { Cabalgatas. }\end{array}$ \\
\hline
\end{tabular}

Tabla 13 Competencia Directa - Autoria Global Glamping

\section{Competencia Sustituta - Alojamientos Ecoturísticos}

\begin{tabular}{|c|c|c|c|}
\hline $\begin{array}{c}\text { Nombre de la } \\
\text { empresa }\end{array}$ & Ubicación & Descripción & Actividades \\
\hline $\begin{array}{l}\text { Palmari Ecolodge } \\
\text { PALMARI }\end{array}$ & $\begin{array}{l}\text { Se encuentra } \\
\text { ubicado entre } \\
\text { Leticia y Tabatinga } \\
\text { Brasil }\end{array}$ & $\begin{array}{l}\text { Se caracteriza por ser un hotel } \\
\text { en donde sus casas son } \\
\text { hechas con productos } \\
\text { naturales y por la constante } \\
\text { interacción con la fauna y } \\
\text { flora del Amazonas. }\end{array}$ & $\begin{array}{l}\text { Recorridos por la selva } \\
\text { Visitas a comunidades } \\
\text { indígenas } \\
\text { Turismo de aventura } \\
\text { Observación de aves }\end{array}$ \\
\hline $\begin{array}{c}\text { Ecohotel Paraíso } \\
\text { verde }\end{array}$ & $\begin{array}{l}\text { Se encuentra } \\
\text { ubicado en el } \\
\text { departamento del } \\
\text { Quindío }\end{array}$ & $\begin{array}{l}\text { Se caracteriza por usar } \\
\text { elementos de guadua y por } \\
\text { exponer la cultura paisa. }\end{array}$ & $\begin{array}{l}\text { Spa } \\
\text { Tour avistamiento de } \\
\text { aves } \\
\text { Recorridos por la } \\
\text { región } \\
\text { Deportes de aventura }\end{array}$ \\
\hline El Almejal & $\begin{array}{l}\text { Se encuentra } \\
\text { ubicado en el } \\
\text { Choco Colombiano }\end{array}$ & $\begin{array}{l}\text { Se caracteriza por ser unos de } \\
\text { los mejores hoteles en cuanto } \\
\text { a hospedaje sostenible, ya que } \\
\text { su territorio es casi todo } \\
\text { reserva natural }\end{array}$ & $\begin{array}{l}\text { Caminatas Educativas } \\
\text { Senderos Ecológicos } \\
\text { Actividades lúdicas }\end{array}$ \\
\hline
\end{tabular}




\begin{tabular}{|c|c|c|c|}
\hline $\begin{array}{c}\text { La casa de francois } \\
\text { Ge eincis }\end{array}$ & $\begin{array}{l}\text { Se encuentra } \\
\text { ubicado en San } \\
\text { Agustín Huila }\end{array}$ & $\begin{array}{l}\text { Se caracteriza por su comida } \\
\text { ya que utiliza vegetales que } \\
\text { se cultivan de manera } \\
\text { orgánica }\end{array}$ & $\begin{array}{l}\text { Tours por la zona } \\
\text { Alquiler de caballos }\end{array}$ \\
\hline
\end{tabular}

Con el fin de analizar la información obtenida anteriormente, se discrimina está en una serie de aspectos para realizar un diagnóstico más detallado usando la doctrina del “Análisis de Porter”, donde se desglosará cada una de las 5 fuerzas de las cuales se compone esta teoría.

\section{Análisis de Porter}

El análisis de las 5 fuerzas de Porter, es un modelo estratégico el cual establece un marco con la finalidad de analizar el nivel de competencia dentro de la industria y en base a estas, se desarrolla diferentes estrategias en pro del crecimiento del negocio. Estas 5 fuerzas son:

1. Poder de Negociación de los Compradores o Clientes

2. Poder de Negociación de los Proveedores o Vendedores

3. Amenaza de nuevos Competidores Entrantes

4. Amenaza de productos Sustitutos

5. Rivalidad entre los Competidores 


\section{Estructura de las 5 Fuerzas de Porter}

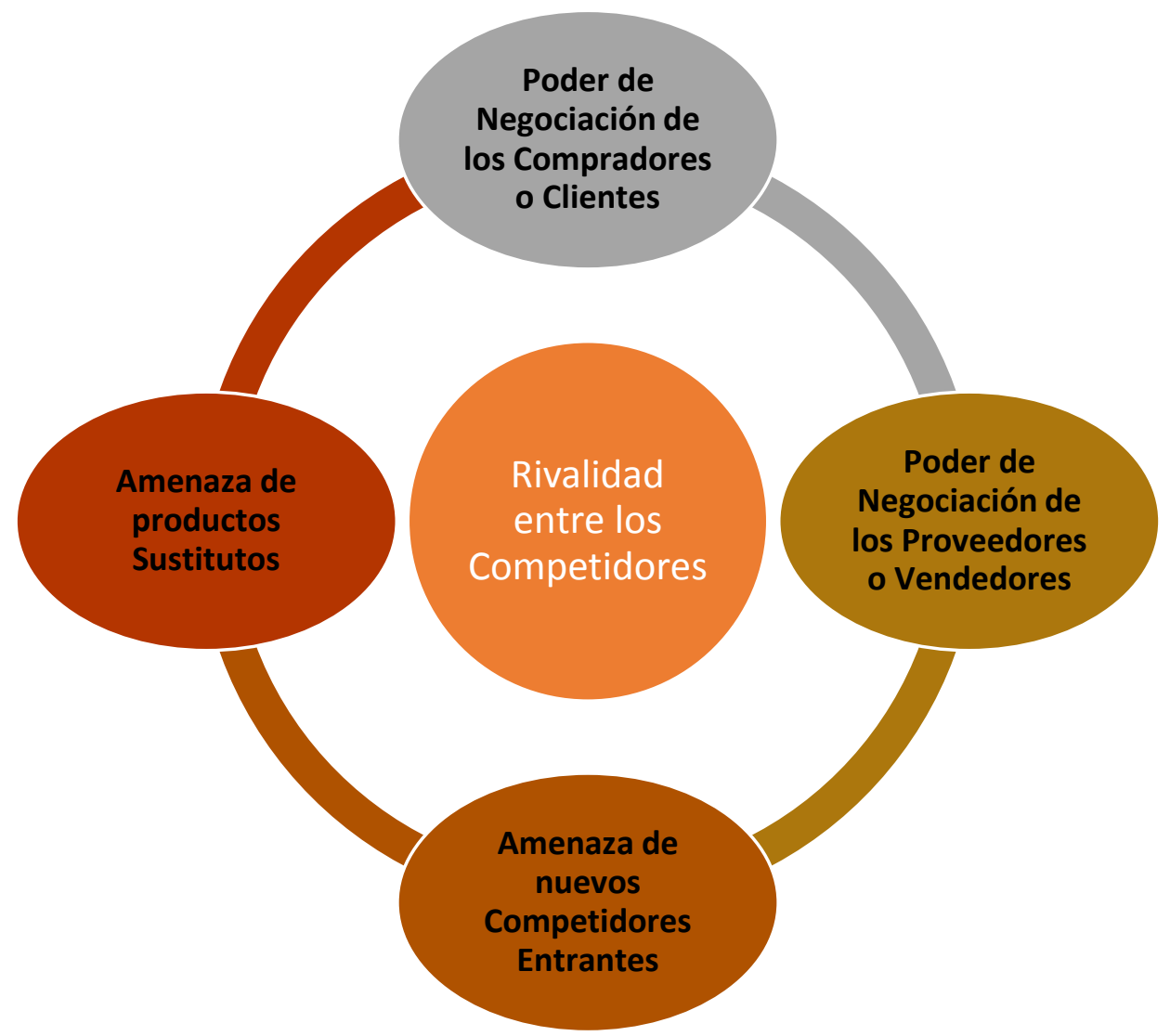

Ilustración 19: Estructuras 5 Fuerzas de Porter - Autoría Global Glamping

\section{Poder de Negociación de los Compradores o Clientes}

El poder que estos ejercen no es tan alto, ya que se realizo es respectivo estudio en el cual la población está de acuerdo con pagar un valor que se encuentra en la media del mercado al cual nos estamos enfocando, adicionalmente, podemos identificar diversas estrategias que serán de vital importancia para diferenciar nuestro servicio de los otros reducir de manera significativa el poder negociación de los compradores con el fin de que estos se adapten a las estrategias interpuestas por Global Glamping.

O Ofrecer un servicio postventa en el cual haber asistido por primera vez a hospedarse y usar nuestros servicios le dé la oportunidad de asistir nuevamente dentro de un 
rango de tiempo (30 días calendario) de asistir nuevamente con un tercer acompañante totalmente gratis.

- Buscar siempre la manera de realizar innovación y conseguir aliados estratégicos para complementar los servicios que ofrece Global Glamping.

- Buscar canales alternativos de comunicación para llegar al cliente, herramientas Electrónicas, publicidad BTL, publicidad en universidades y empresas como estrategias de ventas en concesión.

\section{Poder de Negociación de los Proveedores o Vendedores}

El nivel de Negociación por parte de los proveedores es bajo y teniendo en cuenta que estos son pocos, su afectación en el precio no es directa y de presentarse algún tipo de inconveniente o aumento en los productos que proveen, se realizara la gestión de búsqueda de un proveedor que supla con la necesidad esto claro está tomado como parte de un plan de continuidad para que no se vea reflejado una pausa en la operación.

\section{Amenaza de nuevos Competidores Entrantes}

Teniendo en cuenta que no somos el primer negocio que presenta una actividad de camping con comodidades varias (esto según el cuadro de competencias directas que se observó anteriormente), hay que tener claro que buscar la adecuación o el lugar donde se va a implementar el servicio es complejo y costoso, causa por la que Global Glamping no se ve afectada pese a que el terreno es propio, adicionalmente y tomando como referencia aquellos puntos los cuales resalta Michael Porter en este análisis, observamos que nos destacamos por presentar un servicio que cuenta con un grado de diferenciación frente a nuestras competencias existentes y de compleja superación por parte de los posibles 
competidores entrantes, donde buscamos destacarnos por presentar un lugar de alojamiento normalmente no conocido, una variedad de actividades cuya finalidad es la conexión total con la naturaleza y una buena calidad prestación de servicio por parte de toda la organización tanto a sus clientes internos como externos.

Igualmente para la prestación de todos estos servicios de calidad que ofrece implementar Global Glamping, se necesita de una inversión inicial amplia para la puesta en marcha de su operación, es por este tipo de aspectos que la competencia posiblemente siempre exista pero no sea una preocupación siempre y cuando se implemente siempre la creatividad e innovación en los servicios.

\section{Amenaza de productos Sustitutos}

Posiblemente tenemos cierto grado de amenaza en cuanto a una inesperada caída de precios por parte de la competencia sustituta, pero tenemos la ventaja de que estos no se encuentran en la región donde prestamos el servicio, por ende generaremos planes para el posicionamiento de marca con el fin de no tener que preocuparnos por la caída de precio de dicha competencia ya que el cliente pagara por algo de calidad que no obtendrá en otros establecimientos.

\section{Rivalidad entre los Competidores}

Aunque en la región no se encuentra una amplia cantidad de competidores tenemos claro que la manera como se publicite el negocio es de vital importancia para liderar en este tipo de negocio y generar una diferenciación ante la competencia, por otra parte, el precio es un ítem con el cual tenemos que movernos frecuentemente con la posibilidad de llegar a un punto donde se pueda implementar el servicio en todos los días de la semana y 
abarquemos mayores alianzas con entidades buscando ingresos fijos en periodos de tiempos ya sean semanales, mensuales o trimensuales. Este tipo de estrategia se puede implementar para dejar de lado la rivalidad que puede presentarse los fines de semana que son los días óptimos para realizar este tipo de actividades por todos los tipos de competidores, con esto abarcaremos una mayor cantidad de clientes potenciales y aumentaremos nuestros ingresos.

\section{Análisis Interno}

Con el fin de establecer un diagnóstico preciso para conocer las Oportunidades, Debilidades, Amenazas y Fortalezas de la organización se plantea realizar un análisis DOFA y adicionalmente realizar un cruce entre estos aspectos generando una Matriz de Estrategias, la cual será de gran ayuda para validar si nuestras oportunidades y Fortalezas servirán para realizar planes de continuidad y contingencia frente a las Amenazas y las Debilidades que se puedan llegar a presentar.

\section{DOFA}

\section{Fortalezas.}

- Global Glamping estará ubicado en el Municipio de la Calera a 40 minutos de la ciudad de Bogotá.

- Los precios son competitivos y diferenciados con respecto a la competencia.

- $\quad$ Es un servicio que atrae a los clientes ya que es una tendencia nueva en Colombia

- Es una Alternativa turística que no se encuentra saturada en el mercado.

- Tiene acceso a varias actividades turísticas (Cabalgatas, Senderismo,

\section{Debilidades}

- La Compañía Global Glamping es nueva en el mercado.

- Poca experiencia en el Sector de turístico.

- La tendencia de Glamping es nueva, por lo tanto las personas la conocen muy poco.

- No hay posicionamiento en el mercado.

- Falta de experiencia en los empleados en atención al cliente es este tipo de Negocio.

- Deterioro de las vías de acceso ocasionado por las lluvias. 


\begin{tabular}{|c|c|}
\hline $\begin{array}{l}\text { Ciclo montañismo, etc.) } \\
\text { - Es una compañía comprometida } \\
\text { con el medio ambiente. (Bajo } \\
\text { impacto Ambiental) }\end{array}$ & \\
\hline $\begin{array}{l}\text { Oportunidades } \\
\text { - } \quad \text { Glamping es una tendencia a nivel } \\
\text { mundial, en Colombia actualmente } \\
\text { son pocas las compañías que están } \\
\text { ejecutando este tipo de negocio. } \\
\text { - } \quad \text { En el municipio de la Calera no se } \\
\text { ha encontrado alguna compañía que } \\
\text { preste este servicio. } \\
\text { Es una tendencia que propone } \\
\text { contactar a los clientes } \\
\text { directamente con la naturaleza sin } \\
\text { renunciar a la comodidad y } \\
\text { Confort. } \\
\text { Tiene Glampings Innovadores que } \\
\text { llaman la atención de los clientes } \\
\text { por su diseño. } \\
\text { Glamping Global se puede dar a } \\
\text { conocer a través de las diferentes } \\
\text { redes sociales que actualmente } \\
\text { existen. } \\
\text { Se están buscando alianzas con } \\
\text { diferentes compañías que prestan } \\
\text { servicios turísticos como: } \\
\text { Cabalgatas, Parapente, Ciclo } \\
\text { montañismo etc. } \\
\text { Hay una creciente demanda en el } \\
\text { turismo interno }\end{array}$ & $\begin{array}{l}\text { Amenazas } \\
\text { - La capacidad de recursos propios es } \\
\text { limitada. } \\
\text { - En temporada de invierno hay un } \\
\text { difícil acceso donde operará Global } \\
\text { Glamping, especialmente para los } \\
\text { clientes que tienen automóviles de } \\
\text { altura baja. De igual manera este } \\
\text { factor climático puede afectar el } \\
\text { número de visitantes. } \\
\text { - La compañía puede disminuir sus } \\
\text { ingresos en temporada baja. } \\
\text { - Hay incertidumbre de no tener éxito } \\
\text { a ser un negocio nuevo. }\end{array}$ \\
\hline
\end{tabular}

Tabla 15 Análisis DOFA Autoría: Global Glamping

\section{Matriz de Estrategias}

\section{Estrategias FO}

- Global Glamping debe aprovechar su cercanía a la ciudad de Bogotá, para la búsqueda de clientes.

- Glamping Global debe tener

\section{Estrategias DO}

- La compañía debe impulsar esta nueva tendencia en el sector y pensionarse en el mercado, aprovechando que no se encuentran 


\begin{tabular}{|c|c|}
\hline $\begin{array}{l}\text { precios altamente competitivos de } \\
\text { acuerdo a los servicios que vaya a } \\
\text { ofrecer la compañía. }\end{array}$ & $\begin{array}{l}\text { competidores directos en la zona. } \\
\text { - } \\
\text { Se deben adicionar actividades que } \\
\text { estén relacionadas con la } \\
\text { naturaleza. } \\
\text { - } \\
\text { Se debe fortalecer diferentes } \\
\text { alianzas que presten diferentes } \\
\text { actividades turísticas en el sector. }\end{array}$ \\
\hline Estrategias FA & Estrategias DA \\
\hline $\begin{array}{l}\text { - Se deben buscar aliados } \\
\text { estratégicos para ofrecer diferentes } \\
\text { servicios a los clientes y ser más } \\
\text { competitivos. } \\
\text { - } \quad \text { Global Glamping debe innovar } \\
\text { constantemente sus } \\
\text { Servicios, de esta manera hacer un } \\
\text { factor diferencial antes sus posibles } \\
\text { competidores. }\end{array}$ & $\begin{array}{l}\text { - Se debe capacitar a todo el personal } \\
\text { de la compañía en el manejo de } \\
\text { servicio al cliente, especialmente en } \\
\text { el sector turístico. } \\
\text { - } \quad \text { Fortalecer las estrategias de } \\
\text { mercadeo para dar a conocer a } \\
\text { Global Glamping, incursionado en } \\
\text { las redes sociales. } \\
\text { - Se debe buscar alianzas que permita } \\
\text { trimestralmente arreglar las vías de } \\
\text { acceso donde operar Global } \\
\text { Glamping. } \\
\text { - Los principales socios y fundadores } \\
\text { de la compañía se deben capacitar } \\
\text { en negocios turísticos. }\end{array}$ \\
\hline
\end{tabular}

Ilustración 20. Análisis Cruce de Estrategias DOFA. Autoría Global Glamping

\section{Estrategia de Precio}

Frente a todas las estrategias y las comparaciones anteriormente relacionadas, es de vital importante realizar una estrategia de fijación de precios, ya que este no será solo visto como un aspecto generador de beneficios sino con una herramienta de carácter importante para la implementación de estrategias globales para el negocio.

Para realizar una buena fijación de precio sin dejar de lado el "lucro" que es de vital importancia para el crecimiento del negocio y el "valor" que es el aspecto que mide la calidad del servicio, Global Glamping buscó evaluar 6 tipos de aspectos para determinar la 
elección del precio definitivo, a continuación se presenta el esquema propuesto de los aspectos evaluados:

\section{- Aspectos Evaluados para la fijación del Precio}

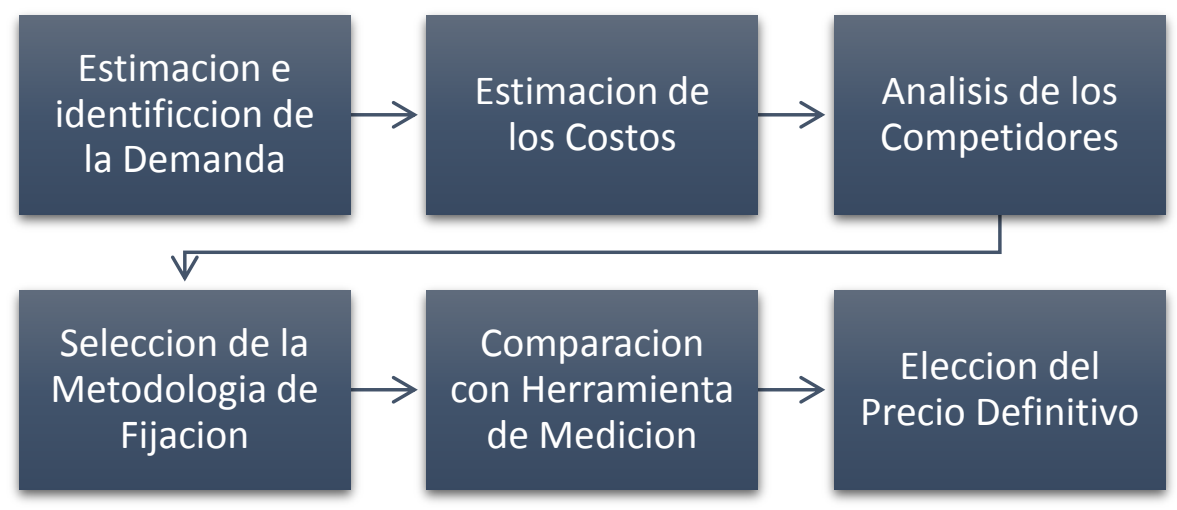

Ilustración 21: Conceptos Evaluados para la Fijación del Precio - Autoría: Global Glamping

\section{Plan Organizacional}

\section{- Organigrama Institucional}

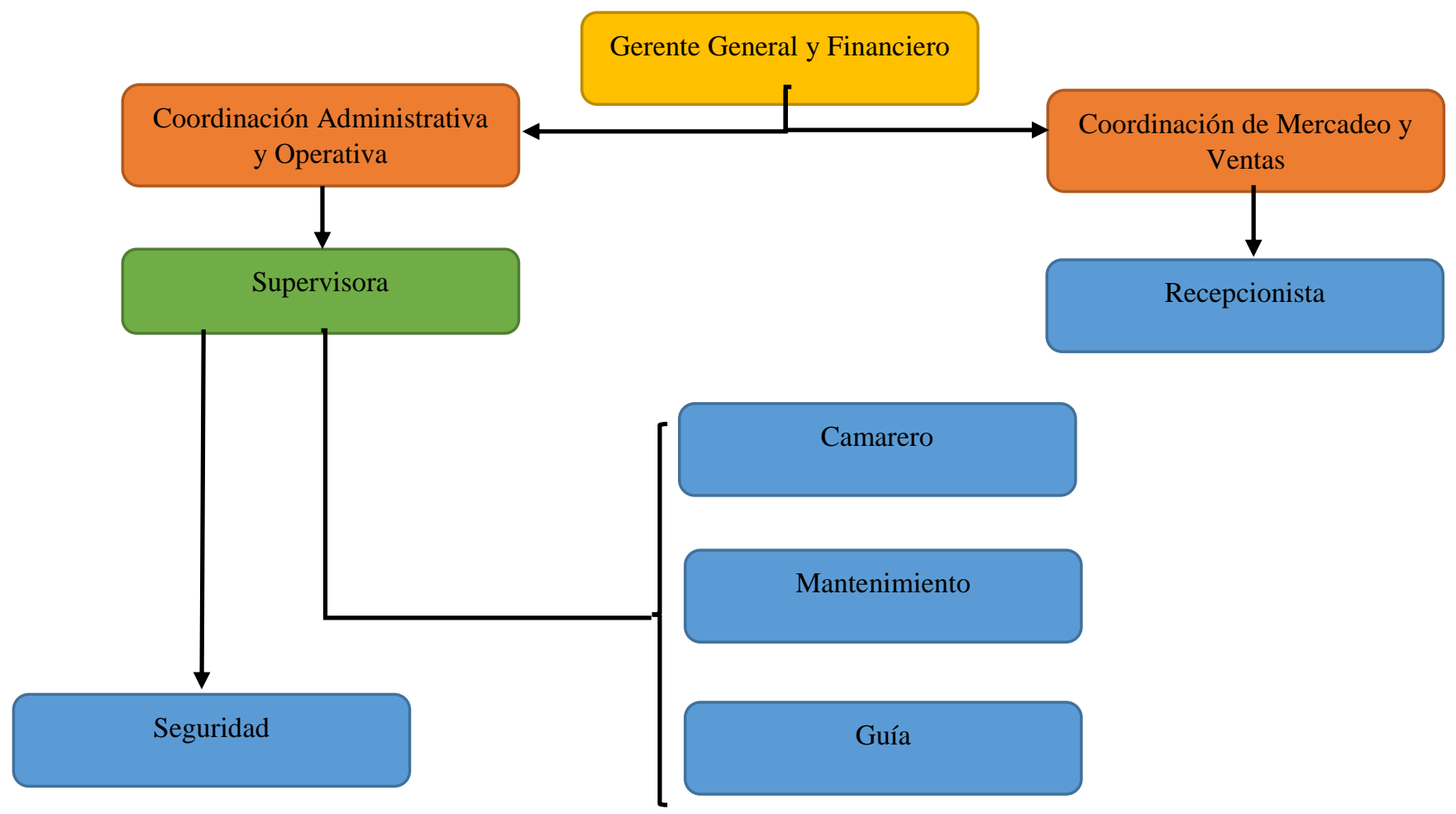

Ilustración 22 Organigrama - Autoria: Global Glamping 


\section{- Descripción de Cargos}

En el siguiente cuadro se hace una descripción de cargos que necesita la compañía Global Glamping, en la cual tomo como referencia el libro "La función de la organización el análisis y descripción, las especificaciones, la matriz para elaborar el perfil de competencias de los cargos u ocupaciones" del Autor "Zayas Agüero Pedro Manuel"

\begin{tabular}{|c|c|}
\hline Nombre del Cargo & Recepcionista \\
\hline Misión del cargo & $\begin{array}{l}\text { Atender a los clientes, contratistas y } \\
\text { funcionarios de la compañía, lleva el } \\
\text { control de llamadas recibidas y dirigirlas a } \\
\text { las distintas áreas de la compañía, es } \\
\text { importante que el vestuario sea el más } \\
\text { adecuado ya que es una de las caras } \\
\text { principales de la compañía. }\end{array}$ \\
\hline Funciones & $\begin{array}{l}\text { - Recepción de Llamadas } \\
\text { - Atención al Público dándoles la } \\
\text { información requerida. } \\
\text { - Recibe la correspondencia } \\
\text { - Elabora informe de las actividades } \\
\text { realizadas }\end{array}$ \\
\hline Requerimientos del Cargo & $\begin{array}{l}\text { - Bachillerato Concluido } \\
\text { - Experiencia mínimo de un año en } \\
\text { recepción }\end{array}$ \\
\hline Subordinados & No aplica \\
\hline
\end{tabular}




\begin{tabular}{|c|c|}
\hline Nombre del Cargo & Coordinador Administrativo y Operativo \\
\hline Misión del cargo & $\begin{array}{l}\text { Dirigir las diferentes actividades operativas y } \\
\text { administrativas que tiene la compañía, garantiza } \\
\text { que las actividades se cumplan según los tiempos } \\
\text { establecidos por el Gerente, además debe } \\
\text { supervisar que la compañía cuente con los insumos } \\
\text { necesarios para ejecutar la operación. }\end{array}$ \\
\hline Funciones & $\begin{array}{l}\text { - Dirigir y Controlar el personal que tienen a cargo. } \\
\text { - Planificar los tiempos que se requiere para el área } \\
\text { de mantenimiento y cocina } \\
\text { - Evaluar las diferentes amenazas que se puedan } \\
\text { generar en la operación, por lo tanto debe buscar } \\
\text { cuáles serán las soluciones }\end{array}$ \\
\hline Requerimientos del Cargo & $\begin{array}{l}\text { - Estudios superiores en ciencias administrativas } \\
\text { - Tener experiencia mínimo de } 3 \text { años en cargos } \\
\text { directivos que se relaciones con áreas de } \\
\text { operaciones } \\
\text { - Debe tener altos niveles de iniciativa y autonomía }\end{array}$ \\
\hline Subordinados & $\begin{array}{l}\text {-Supervisor } \\
\text {-Agente de Seguridad } \\
\text {-Camarero } \\
\text {-Agente de Mantenimiento } \\
\text {-Guía }\end{array}$ \\
\hline
\end{tabular}

Tabla 17 Descripcion de cargo (Coordinador Administrativo) - Autoria: Global Glamping 


\begin{tabular}{|c|c|}
\hline Nombre del Cargo & Gerente General y Financiero \\
\hline Misión del cargo & $\begin{array}{l}\text { La Misión del Gerente General y Financiero es } \\
\text { planificar, dirigir, organizar, coordinar y controlar } \\
\text { los diferentes procesos que tiene la organización, } \\
\text { con el fin de que los objetivos y metas trazadas a } \\
\text { corto, mediano y largo plazo se cumplan, además } \\
\text { debe velar por los recursos financieros que posee la } \\
\text { compañía. }\end{array}$ \\
\hline Funciones & $\begin{array}{l}\text { - Representar Legalmente a la empresa } \\
\text { - Garantizar que las políticas de la compañía se } \\
\text { estén cumpliendo satisfactoriamente } \\
\text { - Organizar la estructura de la Compañía } \\
\text { - Tomar de decisiones de la compañía ya sean } \\
\text { Estratégicas, Financieras o Productivas } \\
\text { - Capacitar a su personal }\end{array}$ \\
\hline Requerimientos del Cargo & $\begin{array}{l}\text { - Estudios Superiores preferiblemente en áreas } \\
\text { administrativas } \\
\text { - Experiencia mayor a } 3 \text { años en sectores } \\
\text { relacionados con el turismo } \\
\text { - Debe tener estudios adicionales en Finanzas, } \\
\text { Contabilidad, Ventas y Comercialización } \\
\text { - Ser una persona creativa y tener la capacidad de } \\
\text { liderar grupos de trabajo. }\end{array}$ \\
\hline Subordinados & $\begin{array}{l}\text { - Coordinador Administrativo y Operativo } \\
\text {-Coordinador Mercadeo y Ventas }\end{array}$ \\
\hline
\end{tabular}

Tabla 18 Descripcion de cargo (Gerente General y Financiero) - Autoria: Global Glamping 


\begin{tabular}{|c|c|}
\hline Nombre del Cargo & Coordinador de Mercadeo y Ventas \\
\hline Misión del cargo & $\begin{array}{l}\text { Preparar un pronóstico de ventas que se tiene cada } \\
\text { mes de igual manera uno de gastos, debe buscar } \\
\text { canales donde se puedan promocionar los servicios } \\
\text { ofrecidos por Global Glamping, además debe } \\
\text { investigar y elaborar planes eco turísticos }\end{array}$ \\
\hline Funciones & $\begin{array}{l}\text { - Realizar seguimiento a los objetivos y metas } \\
\text { trazadas por la compañía en cuanto a ventas del } \\
\text { servicio. } \\
\text { - Elaborar informes al Gerente General de las ventas } \\
\text { realizadas cada mes. } \\
\text { - Organizar reuniones con los directivos para trazar } \\
\text { nuevos objetivos de venta. } \\
\text { - Ejecución de planes de mercadeo } \\
\text { - Tener registro de los clientes potenciales que tiene } \\
\text { la compañía. }\end{array}$ \\
\hline Requerimientos del Cargo & $\begin{array}{l}\text { - Debe tener estudios superiores en ciencias } \\
\text { administrativas, preferiblemente que sea un } \\
\text { profesional en mercadeo. } \\
\text { - Tener mínimo } 3 \text { años de experiencia en cargos } \\
\text { administrativos especialmente en áreas de ventas. } \\
\text { - Debe ser una personas capaz de tomar decisiones y } \\
\text { con la capacidad de proponer nuevas ideas de } \\
\text { marketing }\end{array}$ \\
\hline Subordinados & - Recepcionista \\
\hline
\end{tabular}




\begin{tabular}{|c|c|}
\hline Nombre del Cargo & Agente de Mantenimiento \\
\hline Misión del cargo & $\begin{array}{l}\text { Realizar actividades de siembra y mantenimiento } \\
\text { en los jardines de la compañía, de igual manera } \\
\text { realizar actividades de fumigación en los senderos } \\
\text { de la compañía. }\end{array}$ \\
\hline \multirow[t]{3}{*}{ Funciones } & - Corte de Pasto \\
\hline & $\begin{array}{l}\text { - Barrer, recoger pasto depositándola en los } \\
\text { lugares establecidos }\end{array}$ \\
\hline & - Fumigar lo senderos de la compañía \\
\hline \multirow[t]{2}{*}{ Requerimientos del Cargo } & - Bachillerato Concluido \\
\hline & - Curso de Jardinería certificado \\
\hline Subordinados & No aplica \\
\hline
\end{tabular}




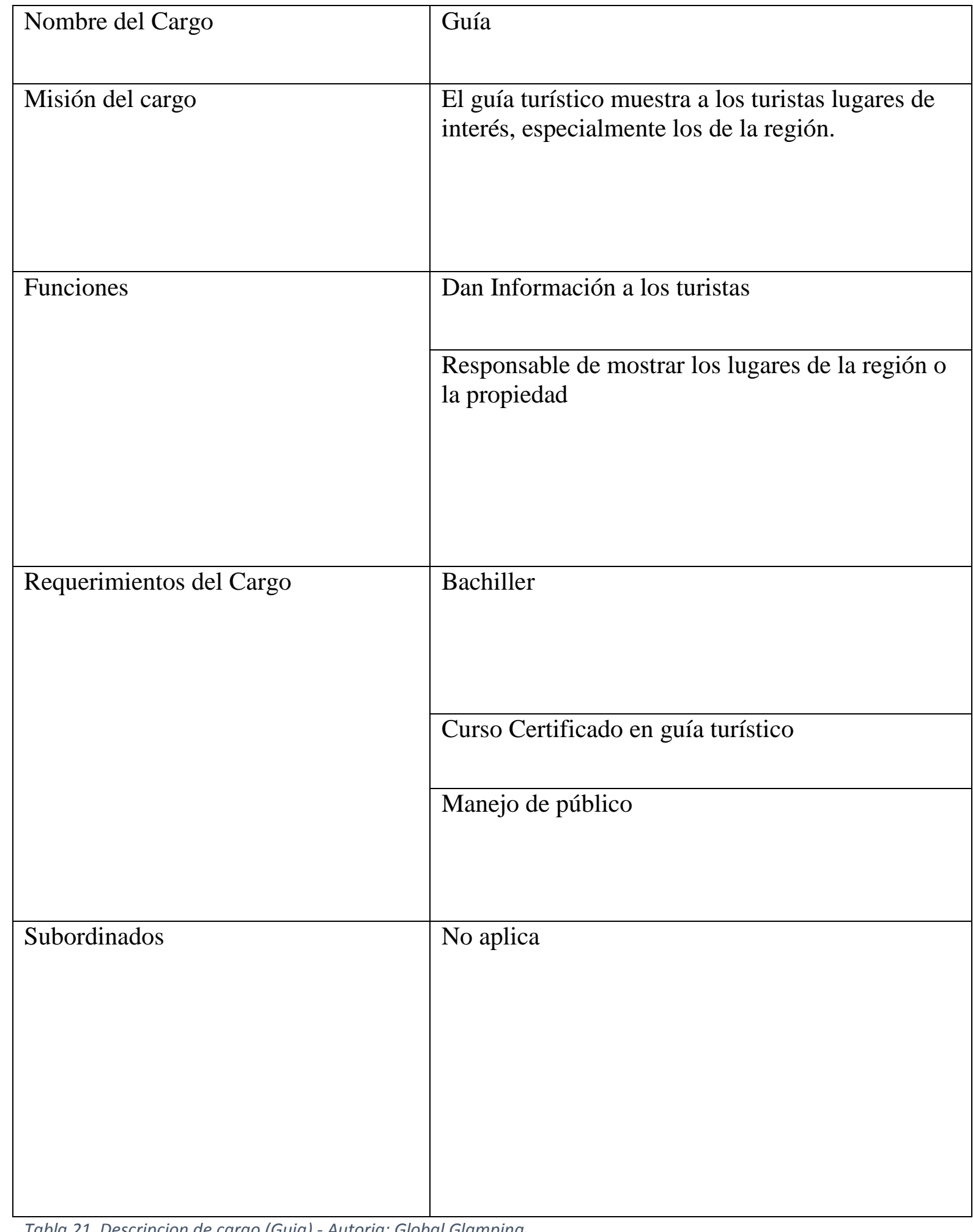




\begin{tabular}{|c|c|}
\hline Nombre del Cargo & Camarero \\
\hline Misión del cargo & $\begin{array}{l}\text { Es responsable de el orden en cada una de los } \\
\text { Glampings }\end{array}$ \\
\hline \multirow[t]{4}{*}{ Funciones } & $\begin{array}{l}\text { Ordena y limpia los cuidados generales de los } \\
\text { Glampings }\end{array}$ \\
\hline & Viste las camas y cambia las sabanas \\
\hline & $\begin{array}{l}\text { Cumple con las normas y requerimientos de la } \\
\text { compañía }\end{array}$ \\
\hline & Realiza inventarios semanalmente \\
\hline \multirow{2}{*}{$\begin{array}{l}\text { Requerimientos del Cargo } \\
\text { Subordinados }\end{array}$} & Bachiller \\
\hline & No aplica \\
\hline
\end{tabular}

Tabla 22 Descripcion de cargo (Camarero) - Autoria: Global Glamping

\begin{tabular}{|l|l|}
\hline Nombre del Cargo & Supervisor \\
\hline Misión del cargo & $\begin{array}{l}\text { Supervisa que la operación se esté cumpliendo } \\
\text { correctamente }\end{array}$ \\
\hline Funciones & Planear el trabajo del día \\
\cline { 2 - 2 } & $\begin{array}{l}\text { Dirigir el personal encargado para el buen } \\
\text { cumplimiento de metas }\end{array}$ \\
\cline { 2 - 2 } & $\begin{array}{l}\text { Controlar las actividades que tiene cada uno de } \\
\text { sus subordinados }\end{array}$ \\
\hline Requerimientos del Cargo & Técnico Administrativo \\
\hline Subordinados & Camarero \\
\cline { 2 - 3 } & Guía \\
\cline { 2 - 3 } & Agente de Seguridad \\
\cline { 2 - 3 } & Agente de Mantenimiento \\
\hline
\end{tabular}




\begin{tabular}{|l|l|}
\hline \multirow{4}{*}{ Nombre del Cargo } & Agente de Seguridad \\
\hline Misión del cargo & Coordina y realiza labores de protección \\
\cline { 2 - 2 } & Vigila la seguridad de la propiedad \\
\cline { 2 - 2 } & $\begin{array}{l}\text { Mantiene el orden dentro de las instalaciones de } \\
\text { la compañía }\end{array}$ \\
\hline \multirow{2}{*}{ Funciones } & Proteger y resguardad los activos de la compañía \\
\cline { 2 - 2 } & $\begin{array}{l}\text { Supervisar cualquier novedad que se presente } \\
\text { fuera de lo normal }\end{array}$ \\
\hline Requerimientos del Cargo & Curso Certificado en Seguridad \\
\cline { 2 - 2 } & Bachiller \\
\cline { 2 - 2 } & Haber prestado servicio militar \\
\hline Subordinados & No aplica \\
\hline
\end{tabular}

Tabla 24 Descripcion de cargo (Agente de Seguridad) - Autoria: Global Glamping

\section{Plan Operacional}

Con la finalidad de presentar un excelente servicio, se muestra a continuación el respectivo flujograma que Global Glamping implementara para la buena atención, seguridad y garantía del cliente. Siendo estas, cualidades que nos identifican como marca que se preocupa 


\section{- Flujograma de la Operacion}

\section{INICIO}

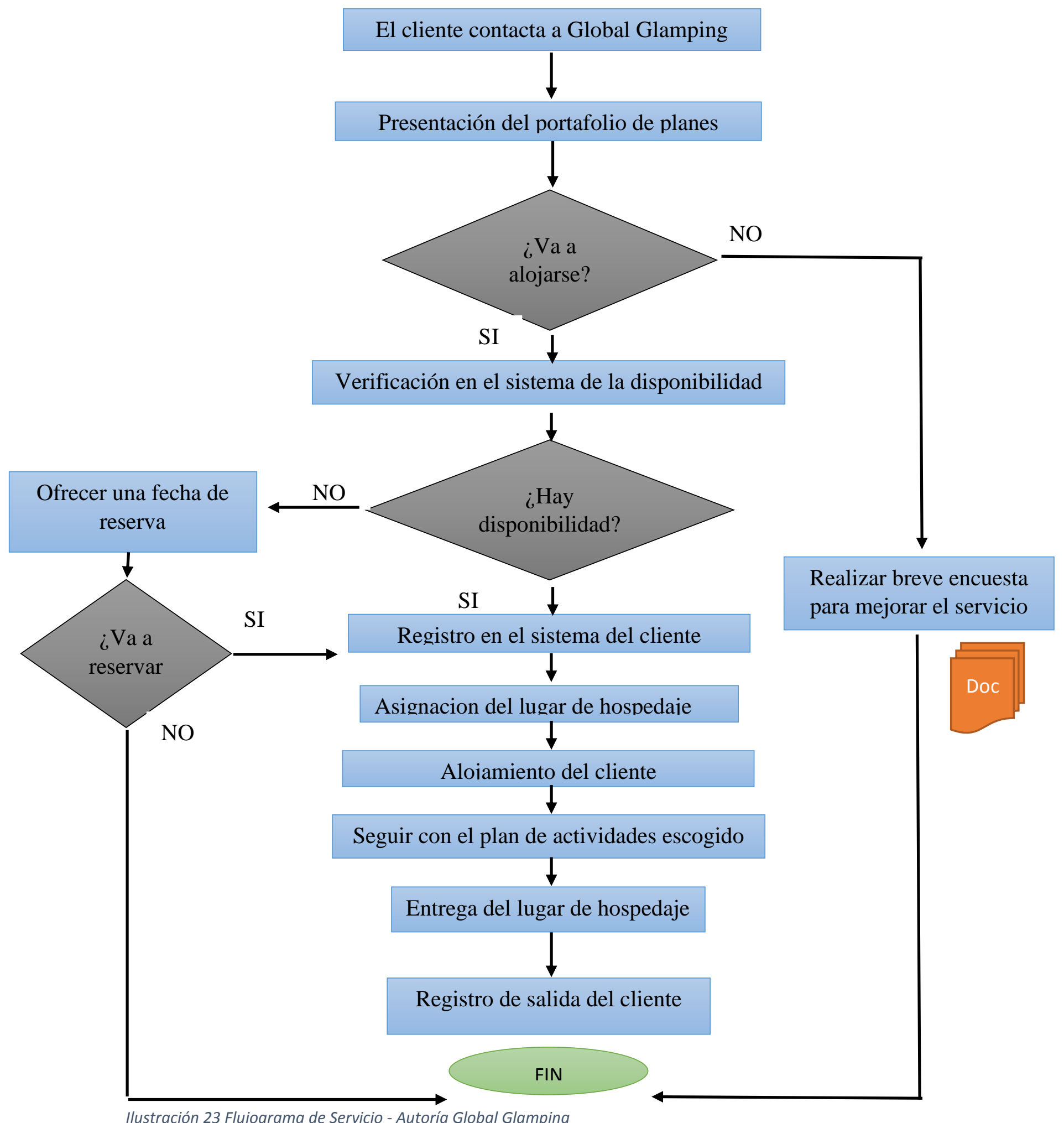




\section{Planeación Financiera}

- Balance de apertura a junio de 2018

\begin{tabular}{|c|cc|}
\hline \multicolumn{2}{|c|}{ ACTIVO JUNIO DE 2018 } \\
\hline Activo Corriente & \multicolumn{2}{c|}{2018 INICIAL } \\
\hline Disponible & $\$$ & 22.226 .000 \\
\hline Total Activo Corriente & $\$$ & $\mathbf{2 2 . 2 2 6 . 0 0 0}$ \\
\hline
\end{tabular}

\begin{tabular}{|l|cr|}
\hline \multicolumn{1}{|c|}{ Activo no Corriente } & \multicolumn{2}{c|}{2018 INICIAL } \\
\hline ACTIVOS FIJOS & & \\
\hline${ }^{*}$ Glampings & $\$$ & 116.100 .000 \\
\hline$*$ Muebles y Enseres & $\$$ & 53.378 .000 \\
\hline$*$ Equipos de Computo & $\$$ & 3.000 .000 \\
\hline *Equipos y Maquinaria & $\$$ & 55.296 .000 \\
\hline *Vehículos & $\$$ & 100.000 .000 \\
\hline
\end{tabular}

\begin{tabular}{|l|ll|}
\hline Total Activo no Corriente & $\$$ & 327.774 .000 \\
\hline Total Activos & $\$$ & 350.000 .000 \\
\hline
\end{tabular}

\section{PASIVO - PATRIMONIO JUNIO DE 2018}

\begin{tabular}{|c|cc|}
\hline PASIVO & 2018 INICIAL \\
\hline Pasivo Corriente & \multicolumn{3}{|c|}{} \\
\hline Obligaciones Financieras & $\$$ & 150.000 .000 \\
\hline Total Pasivo Corriente & $\$$ & 150.000 .000 \\
\hline Total Pasivos & $\$$ & 150.000 .000 \\
\hline
\end{tabular}

\begin{tabular}{|c|cc|}
\hline PATRIMONIO & 2018 INICIAL \\
\hline Aportes Sociales & $\$$ & 200.000 .000 \\
\hline Total Patrimonio & $\$$ & 200.000 .000 \\
\hline
\end{tabular}
Total Pasivo + Patrimonio
$\$$
350.000 .000 
- Balance general comparativo $2018-2022$

GLOBAL GLAMPING

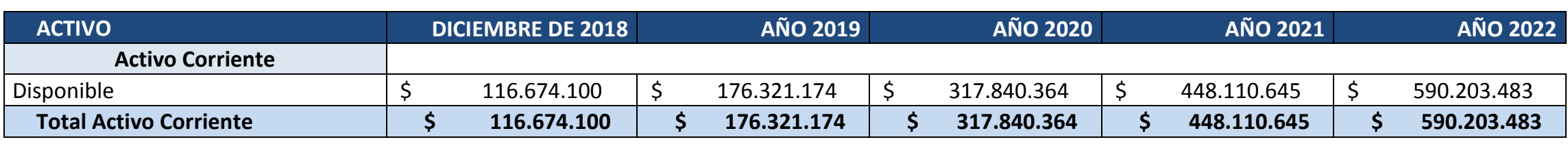

\begin{tabular}{|c|c|c|c|c|c|c|c|c|c|c|}
\hline Activo no Corriente & & & & & & & & & & \\
\hline Activo Fijo & $\$$ & 327.774 .000 & $\$$ & 327.774 .000 & $\$$ & 327.774 .000 & $\$$ & 327.774 .000 & $\$$ & 327.774 .000 \\
\hline Glampings & $\$$ & 116.100 .000 & $\$$ & 116.100 .000 & $\$$ & 116.100 .000 & $\$$ & 116.100 .000 & $\$$ & 116.100 .000 \\
\hline Muebles y Enseres & $\$$ & 53.378 .000 & $\$$ & 53.378 .000 & $\$$ & 53.378 .000 & $\$$ & 53.378 .000 & $\$$ & 53.378 .000 \\
\hline Equipos de Computo & $\$$ & 3.000 .000 & $\$$ & 3.000 .000 & $\$$ & 3.000 .000 & $\$$ & 3.000 .000 & $\$$ & 3.000 .000 \\
\hline Equipos y Maquinaria & $\$$ & 55.296 .000 & $\$$ & 55.296 .000 & $\$$ & 55.296 .000 & $\$$ & 55.296 .000 & $\$$ & 55.296 .000 \\
\hline Vehiculos & $\$$ & 100.000 .000 & $\$$ & 100.000 .000 & $\$$ & 100.000 .000 & $\$$ & 100.000 .000 & $\$$ & 100.000 .000 \\
\hline Total Activo no Corriente & $\$$ & 327.774 .000 & $\$$ & 327.774 .000 & $\$$ & 327.774 .000 & $\$$ & 327.774 .000 & $\$$ & 327.774 .000 \\
\hline \multicolumn{11}{|l|}{ Depresiacion } \\
\hline Glampings & $\$$ & 11.610 .000 & $\$$ & 23.220 .000 & $\$$ & 34.830 .000 & $\$$ & 46.440 .000 & $\$$ & 58.050 .000 \\
\hline Muebles y Enseres & $\$$ & 5.337 .800 & $\$$ & 10.675 .600 & $\$$ & 16.013 .400 & $\$$ & 21.351 .200 & $\$$ & 26.689 .000 \\
\hline Equipos de Computo & $\$$ & 600.000 & $\$$ & 1.200 .000 & $\$$ & 1.800 .000 & $\$$ & 2.400 .000 & $\$$ & 3.000 .000 \\
\hline Equipos y Maquinaria & $\$$ & 5.529 .600 & $\$$ & 11.059 .200 & $\$$ & 16.588 .800 & $\$$ & 22.118 .400 & $\$$ & 27.648 .000 \\
\hline Vehiculos & $\$$ & 20.000 .000 & $\$$ & 40.000 .000 & $\$$ & 60.000 .000 & $\$$ & 80.000 .000 & $\$$ & 100.000 .000 \\
\hline Total Depreciacion Act No Cte & $\$$ & 43.077 .400 & $\$$ & 86.154 .800 & $\$$ & 129.232 .200 & $\$$ & 172.309 .600 & $\$$ & 215.387 .000 \\
\hline
\end{tabular}

\begin{tabular}{|l|l|l|l|l|l|l|l|l|}
\hline Total Activo no Corriente & $\$$ & 284.696 .600 & $\$$ & 241.619 .200 & $\$$ & 198.541 .800 & $\$ 155.464 .400$ & $\$ 112.387 .000$
\end{tabular}

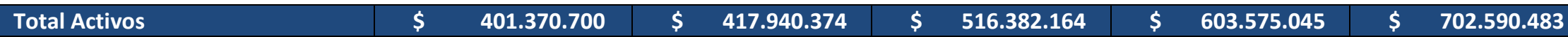


- Balance general comparativo 2018 - 2022

GLOBAL GLAMPING

\begin{tabular}{|c|c|c|c|c|c|c|c|c|c|c|}
\hline PASIVO & \multicolumn{3}{|c|}{ DICIEMBRE DE 2018} & \multicolumn{2}{|l|}{ AÑO 2019} & \multicolumn{2}{|l|}{ AÑO 2020} & \multicolumn{2}{|l|}{ AÑO 2021} & AÑO 2022 \\
\hline Pasivo Corriente & & & & & & & & & & \\
\hline Obligaciones Financieras & $\$$ & 150.000 .000 & $\$$ & 120.000 .000 & $\$$ & 90.000 .000 & $\$$ & 60.000 .000 & $\$$ & 30.000 .000 \\
\hline impuestos & $\$$ & 16.952 .331 & $\$$ & 20.962 .262 & $\$$ & 49.303 .337 & $\$$ & 54.943 .752 & $\$$ & 60.706 .533 \\
\hline Total Pasivo Corriente & $\$$ & 166.952.331 & $\$$ & 140.962 .262 & $\$$ & 139.303.337 & $\$$ & 114.943 .752 & $\$$ & 90.706 .533 \\
\hline Total Pasivos & $\$$ & 166.952 .331 & $\$$ & 140.962 .262 & $\$$ & 139.303.337 & $\$$ & 114.943 .752 & $\$$ & 90.706 .533 \\
\hline PATRIMONIO & & MBRE DE 2018 & & AÑ̃ 2019 & & AÑO 2020 & & AÑO 2021 & & AÑO 2022 \\
\hline Aportes Sociales & $\$$ & 200.000 .000 & $\$$ & 200.000 .000 & $\$$ & 200.000 .000 & $\$$ & 200.000 .000 & $\$$ & 200.000 .000 \\
\hline utilidad del ejercicio & $\$$ & 34.418 .369 & $\$$ & 42.559 .743 & $\$$ & 100.100 .715 & $\$$ & 111.552 .466 & $\$$ & 123.252 .657 \\
\hline utilidad acumulada & $\$$ & - & $\$$ & 34.418 .369 & $\$$ & 76.978 .112 & $\$$ & 177.078 .827 & $\$$ & 288.631 .293 \\
\hline Total Patrimonio & $\$$ & 234.418.369 & $\$$ & 276.978 .112 & $\$$ & 377.078 .827 & $\$$ & 488.631 .293 & $\$$ & 611.883 .951 \\
\hline
\end{tabular}

Total Pasivo + Patrimonio

$\$ \quad 401.370 .700$

$\$ \quad 417.940 .374$

$\$ \quad 516.382 .164$

$\$ \quad 603.575 .045$

$\$ 702.590 .483$

Tabla 26 Balance General - Autoria: Global Glamping 
- Estado de resultados comparativo 2018 -2022

GLOBAL GLAMPING

\begin{tabular}{|c|c|c|c|c|c|c|c|c|}
\hline Ingresos & \multicolumn{2}{|c|}{2 semestre 2018} & \multicolumn{2}{|r|}{2019} & \multicolumn{2}{|r|}{2020} & 2021 & 2022 \\
\hline Ventas & $\$$ & 132.000 .000 & & $\$ 282.240 .000$ & $\$$ & 370.440 .000 & $\$ \quad 388.962 .000$ & $\$ \quad 408.410 .400$ \\
\hline Otros ingresos 1 (Alianzas) & $\$$ & 2.664 .000 & & 5.434 .560 & $\$$ & 5.543 .251 & 5.654 .116 & 5.767 .199 \\
\hline Ventas netas & $\$$ & 134.664 .000 & & $\$ 287.674 .560$ & $\$$ & 375.983 .251 & $\$ \quad 394.616 .116$ & $\$ \quad 414.177 .599$ \\
\hline COSTOS & \multicolumn{2}{|c|}{2 semestre 2018} & \multicolumn{2}{|r|}{2019} & \multicolumn{2}{|r|}{2020} & 2021 & 2022 \\
\hline Arriendo Terreno & $\$$ & 2.400 .000 & & 5.050 .080 & $\$$ & 5.313 .189 & 5.590 .006 & 5.881 .246 \\
\hline Depreciación & $\$$ & 21.538 .700 & & 43.077 .400 & $\$$ & 43.077 .400 & 43.077 .400 & 43.077 .400 \\
\hline Sueldos de personal de planta & $\$$ & 32.438 .000 & & 77.851 .200 & $\$$ & 82.444 .421 & 87.308 .642 & 92.459 .851 \\
\hline Mantenimiento & $\$$ & 1.500 .000 & $\$$ & 3.000 .000 & $\$$ & 3.000 .000 & 3.000 .000 & 3.000 .000 \\
\hline SERVICIOS PUBLICOS & $\$$ & 6.212 .700 & $\$$ & 12.736 .035 & $\$$ & 13.372 .837 & 14.041.479 & 14.743 .553 \\
\hline *Acueducto & & $\$ 2.000 .000$ & $\$$ & 4.100 .000 & $\$$ & 4.305 .000 & 4.520 .250 & 4.746 .263 \\
\hline *Luz & & $\$ 1.000 .000$ & $\$$ & 2.050 .000 & $\$$ & 2.152 .500 & 2.260 .125 & 2.373 .131 \\
\hline *Gas & & $\$ 1.800 .000$ & $\$$ & 3.690 .000 & & 3.874 .500 & 4.068 .225 & 4.271 .636 \\
\hline${ }^{*}$ Teléfono fijo & & $\$ 300.000$ & $\$$ & 615.000 & $\$$ & 645.750 & 678.038 & 711.939 \\
\hline${ }^{*}$ Teléfono celular e internet & & $\$ 1.112 .700$ & & 2.281 .035 & & 2.395 .087 & 2.514 .841 & 2.640 .583 \\
\hline Beneficio bruto & $\$$ & 70.574 .600 & $\$ 1$ & 45.959 .845 & $\$ 2 i$ & 28.775 .404 & $\$ 241.598 .590$ & $\$ 255.015 .549$ \\
\hline GASTOS OPERACIONALES & $2 \mathrm{se}$ & emestre 2018 & & 2019 & & 2020 & 2021 & 2022 \\
\hline Salarios & $\$$ & 16.247 .100 & $\$$ & 38.993 .040 & & 41.722 .553 & 44.643.131 & 47.768.151 \\
\hline Publicidad & $\$$ & 2.956 .800 & $\$$ & 5.644 .800 & $\$$ & 7.408 .800 & 7.779 .240 & 8.168 .208 \\
\hline Total de gastos de operaciones & $\$$ & 19.203 .900 & & 44.637 .840 & $\$ 4$ & 49.131.353 & $\$ \quad 52.422 .371$ & $\$ \quad 55.936 .359$ \\
\hline Utilidad Operacional & $\$$ & 51.370 .700 & $\$$ & 101.322 .005 & & 179.644.052 & $\$ \quad 189.176 .218$ & $\$ \quad 199.079 .190$ \\
\hline Gastos Financieros(Intereses & & & & 37.800 .000 & $\$ 30$ & $.240 .000,00$ & $\$ 22.680 .000,00$ & $\$ 15.120 .000,00$ \\
\hline Utilidades Antes de Impuestos & $\$$ & 51.370 .700 & $\$$ & 63.522 .005 & & 149.404 .052 & $\$ 166.496 .218$ & $\$ 183.959 .190$ \\
\hline Impuesto de renta & $\$$ & 16.952 .331 & $\$$ & 20.962 .262 & $\$$ & 49.303 .337 & 54.943 .752 & 60.706 .533 \\
\hline Utilidad Neta & $\$$ & 34.418 .369 & $\$$ & 42.559 .743 & $\$$ & 100.100.715 & $\$ 111.552 .466$ & $\$ 123.252 .657$ \\
\hline
\end{tabular}

Tabla 27 Estado de Resultados - Autoria: Global Glamping 
- Flujo de caja comparativo 2018 - 2022

GLOBAL GLAMPING

\begin{tabular}{|c|c|c|c|c|c|c|c|c|}
\hline \multirow{2}{*}{$\begin{array}{l}\text { CONCEPTO } \\
\text { Saldo Inicial }\end{array}$} & \multicolumn{2}{|c|}{$\begin{array}{l}20182 \\
\text { SEMESTRE }\end{array}$} & 2018 INICIAL & 2018 TOTAL & 2019 & 2020 & 2021 & 2022 \\
\hline & & & $\$$ & $\$ 22.226 .000$ & $\$ 116.674 .100$ & $\$ 178.846 .214$ & $\$ 323.021 .999$ & $\$ 450.446 .868$ \\
\hline \multicolumn{9}{|l|}{ Ingresos } \\
\hline Aportes Socios & & & $\$ 200.000 .000$ & $\$ 200.000 .000$ & & & & \\
\hline Prestamos recibidos & & & $\$ 150.000 .000$ & $\$ 150.000 .000$ & & & & \\
\hline Ingresos Operacionales & $\$$ & 134.664 .000 & & $\$ 134.664 .000$ & $\$ 287.674 .560$ & $\$ 375.983 .251$ & $\$ 394.616 .116$ & $\$ 414.177 .599$ \\
\hline Total Ingresos & $\$$ & 134.664 .000 & $\$ 350.000 .000$ & $\$ 484.664 .000$ & $\$ 287.674 .560$ & $\$ 375.983 .251$ & $\$ 394.616 .116$ & $\$ 414.177 .599$ \\
\hline \multicolumn{9}{|l|}{ Egresos } \\
\hline Activos Fijos & & & $\$ 327.774 .000$ & $\$ 327.774 .000$ & & & & \\
\hline Arriendo Terreno & $\$$ & 2.400 .000 & & 2.400 .000 & 2.525 .040 & 2.656 .595 & 2.795 .003 & 2.940 .623 \\
\hline Sueldos de personal de planta & $\$$ & 32.438 .000 & & $\$ 32.438 .000$ & $\$ 77.851 .200$ & $\$ 82.444 .421$ & $\$ 87.308 .642$ & $\$ 92.459 .851$ \\
\hline Sueldos Administrativos & $\$$ & 16.247 .100 & & $\$ 16.247 .100$ & $\$ \quad 38.993 .040$ & $\$ \quad 41.722 .553$ & $\$ \quad 44.643 .131$ & $\$ \quad 47.768 .151$ \\
\hline Publicidad & $\$$ & 2.956 .800 & & 2.956 .800 & 5.644 .800 & 7.408 .800 & 7.779 .240 & 8.168 .208 \\
\hline Mantenimiento & $\$$ & 1.500 .000 & & 1.500 .000 & 3.000 .000 & 3.000 .000 & 3.000 .000 & 3.000 .000 \\
\hline Servicios públicos & $\$$ & 6.900 .000 & & 6.900 .000 & $\$ 12.736 .035$ & $\$ 13.372 .837$ & $\$ 14.041 .479$ & $\$ 14.743 .553$ \\
\hline Abono de Capital de Prestamos* & & & & $\$$ & $\$ 30.000 .000$ & $\$ 30.000 .000$ & $\$ 30.000 .000$ & $\$ 30.000 .000$ \\
\hline Pago de Intereses & & & & $\$$ & $\$ 37.800 .000$ & $\$ 30.240 .000$ & $\$ 22.680 .000$ & $\$ 15.120 .000$ \\
\hline Pago de Impuesto & & & & & $\$ \quad 16.952 .331$ & $\$ \quad 20.962 .262$ & $\$ \quad 54.943 .752$ & $\$ \quad 60.706 .533$ \\
\hline Total Egresos & $\$$ & 62.441 .900 & $\$ 327.774 .000$ & $\$ 390.215 .900$ & $\$ 225.502 .446$ & \$ 231.807.467 & \$ 267.191.247 & $\$ 274.906 .918$ \\
\hline Ingresos Menos Egresos & $\$$ & 72.222 .100 & $\$ \quad 22.226 .000$ & $\$ 94.448 .100$ & $\$ \quad 62.172 .114$ & $\$ 144.175 .785$ & \$ 127.424 .869 & $\$ 139.270 .680$ \\
\hline Saldo Final de Caja & $\$$ & 72.222 .100 & $\$ \quad 22.226 .000$ & $\$ 116.674 .100$ & $\$ 176.321 .174$ & $\$ 317.840 .364$ & $\$ 448.110 .645$ & $\$ 590.203 .483$ \\
\hline
\end{tabular}


- Flujo de caja libre comparativo 2018 - 2022

GLOBAL GLAMPING

\begin{tabular}{|c|c|c|c|c|c|c|c|c|c|c|c|c|c|}
\hline FLUJO DE CAJA LIBRE & & & \multicolumn{2}{|c|}{2018 INICIAL } & \multicolumn{2}{|r|}{2018} & \multicolumn{2}{|r|}{2019} & \multicolumn{2}{|r|}{2020} & \multicolumn{2}{|r|}{2021} & 2022 \\
\hline Ingresos - Egresos & $\$$ & 72.222 .100 & $\$$ & 22.226 .000 & $\$$ & 94.448 .100 & $\$$ & 62.172 .114 & $\$$ & 144.175 .785 & & 127.424 .869 & $\$ 139.270 .680$ \\
\hline Aporte de Capital & $\$$ & - & $\$$ & 200.000 .000 & $\$$ & - & $\$$ & - & $\$$ & - & $\$$ & - & $\$$ \\
\hline Creditos Recibidos & $\$$ & - & $\$$ & 150.000 .000 & $\$$ & - & $\$$ & - & $\$$ & - & $\$$ & - & $\$$ \\
\hline Pago de Capital & $\$$ & - & $\$$ & - & $\$$ & - & $\$$ & 30.000 .000 & $\$$ & 30.000 .000 & $\$$ & 30.000 .000 & $\$ 30.000 .000$ \\
\hline Pago de Intereses & $\$$ & - & $\$$ & - & $\$$ & - & $\$$ & 37.800 .000 & $\$$ & 30.240 .000 & $\$$ & 22.680 .000 & $\$ \quad 15.120 .000$ \\
\hline TOTAL FLUJO DE CAJA LIBRE & $\$$ & 72.222 .100 & & $327.774 .000)$ & $\$$ & 94.448 .100 & & 129.972 .114 & & 204.415 .785 & & 180.104 .869 & $\$ 184.390 .680$ \\
\hline
\end{tabular}

- Valor presente neto (VPN)

VALOR PRESENTE NETO (VPN)

$\$ 355.323 .596$

$\$ 27.549 .596$

- Tasa de rentabilidad interna (TIR)

TASA DE RENTABILIDAD INTERNA (TIR)

$34 \%$

Tabla 28 Tasa Interna de Retorno (TIR) - Autoria: Global Glamping 


\section{Conclusiones}

Como lo demuestra el Balance General el crecimiento que Global Glampin piensa alcanzar en un periodo de 5 años oscila en un crecimiento del $15 \%$ al $16 \%$ aprox. Respectivamente.

Es necesario iniciar, iniciando el proyecto, apalancarse con una entidad bancaria para poder cubrir los diferentes costos y gastos que la operación del servicio requiere

Se identificó la población objetivo con base en la encuesta realizada en la localidad de chapinero la cual cuenta con 122.089 personas según el último censo del Dane (2005), en donde se observó que el mercado potencial de Global Glamping es del 50.3\%, tomando en cuenta todas aquellas personas que ya tienen una profesión se calcula que son un aproximado de 61.410 personas, como resultado en estas cifras se encuestaron 151 personas por consiguiente el $39 \%$ de las personas encuestadas están totalmente de acuerdo en incorporar en sus vacaciones las actividades que ofrece Global Glamping, de igual manera el $37 \%$ está bastante de acuerdo, demostrando que esta nueva tendencia es atractiva para implementarla en el municipio de La Calera.

Con el fin de generar una estructura organizacional correcta se ha realizado una descripción de cargos que proporciona una guía para que todos los funcionarios de la empresa puedan desarrollar de manera más eficiente sus actividades, evitando confusión y pérdida de tiempo, este se complementa con el organigrama propuesto puesto que incluye responsabilidades y actividades a realizar, así como su relación con otros puestos de trabajo lo que hace posible que los funcionarios puedan entender la importancia de trabajar de una manera coordinada con el objetivo de mejorar los procesos. 
Se busca con este proyecto poder mostrarle a las personas a nivel nacional e internacional que decidan visitar Global Glamping, la diversidad de actividades que pueden realizar con su pareja o con su familia conectándose con la naturaleza, siendo atendidos por un grupo de personas capacitadas y entrenadas para brindarles los mejores servicios sintiéndose como en un hotel cinco estrellas.

Se estima en un periodo de 5 años que las personas adquiera el posicionamiento de marca de Global Glamping, caracterizado siempre por la prestación de un buen servicio, la publicidad que se implemente y las innovaciones en las actividades para hacer de este servicio una experiencia inolvidable.

\section{Recomendaciones:}

Las recomendaciones sugeridas a Global Glamping para un adecuado manejo ambiental son los siguientes:

-Instalar canecas para la recolección de residuos sólidos con el fin de que esta actividad se desarrolle de manera efectiva.

-Colocar placas para la identificación de plantas forestales y señalización adecuada para la prevención de riesgos.

-Señalizar puntos estratégicos para la realización de fogatas.

-Realizar capacitaciones continuas a los funcionarios de Global Glamping sobre manejos y cuidados del medio ambiente, con el fin de que puedan trasmitirle estos conocimientos a los clientes.

-Diseñar y realizar una señalización de recorridos. 


\section{Bibliografía}

Airbnb. (s.f.). Glamping colombia. Obtenido de

https://www.airbnb.com.co/rooms/15799286

Calera, A. d. (2017). Alcaldia de la Calera. Obtenido de Alcaldia de la Calera:

http://www.lacalera-cundinamarca.gov.co/MiMunicipio/Paginas/Ecologia.aspx

CITUR. (2017). CENTRO DE INFORMACION TURISTICA DE COLOMBIA. Obtenido de CENTRO DE INFORMACION TURISTICA DE COLOMBIA:

http://webcache.googleusercontent.com/search?q=cache:xHXxPitxmboJ:citur.linkti c.com/estadisticas/df_viajeros_ciudad_destino/all/2+\&cd=2\&hl=es-

$419 \& \mathrm{ct}=\mathrm{clnk} \& \mathrm{gl}=\mathrm{co}$

COMERCIO, M. D. (s.f). MINISTERIO DE INDUSTRIA Y COMERCIO. Obtenido de MINISTERIO DE INDUSTRIA Y COMERCIO:

http://www.mincit.gov.co/publicaciones/16746/definicion_del_sector_turismo_en_c olombia

DANE. (25 de Febrero de 2016). Encuesta de Gasto en Turismo Interno - EGIT. Obtenido de Encuesta de Gasto en Turismo Interno - EGIT:

http://www.dane.gov.co/index.php/estadisticas-por-

tema/servicios/turismo/encuesta-de-gasto-en-turismo-interno-egit

despegar. (s.f.). despegar.com. Obtenido de

https://www.despegar.com.co/hoteles/hl/854/i1/hoteles-en-

bogota\#sorting=best_selling_descending $\&$ stars=4\&page= $1 \&$ view=list 
Dinero, R. (10 de 02 de 2015). Revista Dinero. Obtenido de http://www.dinero.com/actualidad/articulo/estudio-de-la-universidad-nacionalsobre-los-estratos-sociales-y-estereotipos-/218027

Dome, S. (s.f). Shelter Dome. Obtenido de Shelter Dome: http://www.shelterdomos.com/empresa/

Gobierno, S. I. (01 de 03 de 2017). Presidencia de la Republica. Obtenido de Presidencia de la Republica: http://es.presidencia.gov.co/noticia/170301-Datos-clave-de-laindustria-turistica-en-Colombia

Heller, E. (2004). Psicologia del Color (Vol. 1). Barcelona, España: Gustavo Gili.

Hotel, B. B. (s.f.). Bethel Bio Luxury Hotel. Obtenido de https://www.betheltatacoaoficial.com/

IMPULSO.COM, E. (31 de mayo de 2015). Acampar con Lujo. EL IMPULSO.COM, 1.

Infobae. (02 de 04 de 2018). Periodico Infobae. Obtenido de https://www.infobae.com/turismo/2017/06/03/glamping-la-nueva-tendenciahotelera-que-es-furor-entre-los-millennials/

MINCIT. (2017). Informe mensual de Turismo. Cundinamarca. Bogota: Oficina de estudios Economicos.

Ministerio de Comercio, I. y. (28 de Septiembre de 2017). Ministerio de Comercio, Industria y Turismo. Obtenido de Ministerio de Comercio, Industria y Turismo: http://www.mincit.gov.co/publicaciones/39149/turismo_sostenible_vital_para_las_r egiones_ministra_de_comercio 
MINISTERIO DE INDUSTRIA, C. Y. (Julio de 2017). Boletin mensual de Turismo 2017. Obtenido de Boletin mensual de Turismo 2017: http://www.mincit.gov.co/loader.php?1Servicio=Documentos\&lFuncion=verPdf\&id =81855\&name=OEE_OP_Turismo_Julio_25-08-2017.pdf\&prefijo=file

Montes, G. M. (2006). Ecoturismo instrumento de desarrollo sostenible. Obtenido de http://bibliotecadigital.udea.edu.co/bitstream/10495/149/1/EcoturismoInstrumentoD esarrolloSostenible.pdf

NIDDO. (s.f.). NIDDO Suesca. Obtenido de https://www.niddo.co/

OMT, O. M. (2002). Organismo especializado de las Naciones Unidas Organización Mundial del Turismo OMT. Obtenido de Organismo especializado de las Naciones Unidas Organización Mundial del Turismo OMT: http://www2.unwto.org/es/content/ecoturismo-y-areas-protegidas

Proexport. (s.f). Proexport. Obtenido de Proexport: http://www.procolombia.co/especialcolombia-ny-2012/visite-colombia/razones-de-por-qu\%C3\%A9-viajar-colombia

PTP. (Marzo de 2013). PLAN DE NEGOCIO DE TURISMO DE NATURALEZA DE COLOMBIA. Obtenido de PLAN DE NEGOCIO DE TURISMO DE NATURALEZA DE COLOMBIA: https://www.ptp.com.co/documentos/Presentaci\%C3\%B3n\%20Final.pdf

Republica, P. d. (3 de Enero de 2017). Presidencia de la Republica. Obtenido de Presidencia de la Republica: http://es.presidencia.gov.co/noticia/170103-Reformatributaria-dara-impulso-al-turismo-en-municipios-pequenos-del-pais 
Republica, S. G. (2015). BANCO DE LA REPUBLICA. Obtenido de BANCO DE LA REPUBLICA:

http://www.banrepcultural.org/blaavirtual/ayudadetareas/economia/sectores_econo micos

Romero, R. (2014). Marketing. Palmir E.I.R.L.

Sciosia, V. (2015). The Glamping Way to Discover South Africa. Milan: Blurb, Incorporated.

Secretaria de Cultura, R. y. (18 de 05 de 2016). Secretaria de Cultura, Recreacion y Deporte. Obtenido de www.culturarecreacionydeporte.gov.co/es/localidades/chapinero

Trabajo, M. d. (2013). Encuesta Nacional de condiciones de seguridad y salud en el trabajo. Bogota.

Viajala. (s.f.). Viajala. Obtenido de https://viajala.com.co/blog/5-hoteles-ecologicos-encolombia 